June 1977

\title{
Craniofacial Adaptations After Total Maxillary Osteotomy in Macaca Irus: A Cephalometric and Histologic Study
}

Harry L. Legan

Follow this and additional works at: https://opencommons.uconn.edu/sodm_masters

\section{Recommended Citation}

Legan, Harry L., "Craniofacial Adaptations After Total Maxillary Osteotomy in Macaca Irus: A Cephalometric and Histologic Study" (1977). SoDM Masters Theses. 147.

https://opencommons.uconn.edu/sodm_masters/147 


\title{
CRANIOFACIAL ADAPTATIONS AFTER
}

TOTAL MAXILLARY OSTEOTOMY IN MACACA IRUS --

A CEPHALOMETRIC AND HISTOLOGIC STUDY

\author{
Harry L. Legan
}

Submitted in partial fulfillment of the requirements for a Certificate in Orthodontics

Department of Orthodontics University of Connecticui Heal th Center

Farmington, Connecticut 06032

$$
\text { June 21, } 1977
$$




\section{ACKNO:NLEDGEMENT}

The author would like to express his appreciation

to Dr. Ravi Nanda for his valuable assistance in planning and conducting this study.

The author thanks Dr. R. B. James and Dr. Bob Gross of the Department of Maxillofacial Surgery for their help in the surgical aspects of this study. Thanks are also extended to Mr. Michael Messina, Ms. Susan Cowan and Mrs. Jean Gioiele for their technical assistance and help in preparing this manuscript.

This study was supported by NIH Grant \# DE 00283-05. 
INTRODUCTION

The present day orthodontist cannot effectively treat all types of malocclusions and facial disharmonies without the cooperation of the maxillofacial surgeon. Specifically, problems such as skeletal Class II and Class III discrepancies, open bites, facial asymmetries and long face syndrome ${ }^{35}$ often require a combined surgical orthodontic treatment.

Traditionally, the majority of the corrective surgery for maxillofacial disharmonies has been performed in the mandible which often resulted in relapse due to nonstability of altered neuromuscular physio$\operatorname{logy}^{21},{ }^{26},{ }^{27}$ In recent years, maxillary surgical procedures have become popular for effecting more stable and desirable results! ${ }^{1}, 22,23,24$ However, many questions regarding the biologic basis of total or segmental maxillary osteotomy are still unanswered. Bell and his co-workers, ${ }^{4,5}$ in studies using rhesus monkeys as an experimental model, investigated the revascularization and bone healing associated with various maxillary osteotomy procedures. They found a rapid revascularization of bone and teeth with minimal osteonecrosis and ischaemia. They also showed that at the osteotomy site, osseous healing took place within six weeks. This finding was contrary to the popular belief at the time, that after ostectomy, maxilla healed by fibrous union.

Young and Epker ${ }^{36}$ and Stoker and Epker $\equiv^{3}$ evaluated the sinus health, patient acceptance and relapse in patients who had undergone anterior and posterior maxillary osteotomies. They reported very favorable results and maintained that the relapse during the post surgical period was minimal. 
However, in spite of the increasing use of maxillary osteotomy procedures, no study was found in the 1iterature which had made an attempt to investigate their long term stability and other, if any, adaptive changes in the dentofacial complex. The present study was designed to evaluate the post-surgical changes in Macaca irus monkeys after total maxillary osteotomies. The study focused primarily on the following questions:

1. How stable is the new position of the maxilla?

2. What is the nature of maxillary healing?

3. Do teeth continue to erupt into the "increased" interocclusal space?

4. What bony changes occur when mandible is forced to function in a new position? 
MATERIALS AND METHODS

Five young adult female Macaca irus (crab-ea ing) monkeys were used as experimental animals in this study. All monkeys had partially to fully erupted third molars. Their age was determined to be between 5 and 6 years! ${ }^{7}$ They were kept in separate cages at the University of Connecticut vivarium. Their regular diet consisted of high protein monkey chow supplemented with fresh fruit.

For accurate interpretation of cephalometric radiographs, tantalum implants $1.5 \mathrm{~mm}$. long and $.02 \mathrm{~mm}$. in diameter, were placed in predetermined areas of the craniofacial skeleton. ${ }^{6,70}$ The implants were placed on the left side of the following bones under sterile conditions (Fig. 1):

Cranium: $\quad 2$ implants in the frontal bone, 2 in the temporal bone. Maxilla: $\quad$ midline, near incisor apex, in the area of the canine apex, near the first molar apex, Mandible: $\quad$ midline, near incisor apex. distal to canine apex, apical to first molar.

Prior to the surgical procedures, the animals were sedated with Ketamine $10 \mathrm{mg} / \mathrm{kg}$. intramuscularly. A 21 -gauge needle was used to start a continuous infusion of lactated Ringer's solution. This infusion site was also used for administering additional anesthetic agents. Meperidine HCl was then given and followed with an induction dose of methylhexitol sodium. Nasal intubation was accomplished under direct vision. A mixture 
of 70 per cent $\mathrm{N}_{2} \mathrm{O}$ and 30 per cent $\mathrm{O}_{2}$ was used to maintain the anesthetic plane. On occasion it was necessary to incorporate 1 per cent methoxyflurane for short periods. Blood loss and heart rate were closely monitored so that appropriate adjustments of the rate of administration of the I.V. fluids could be made.

A single-stage total maxillary osteotomy (Fig. 2) on the three experimental animals was started with a horizontal incision through the mucoperiosteum extending from one tuberosity to the other. The posterior osteotomy was gained by extraction of second or third molars. The inferior aspect of the osteotomy was started from above the apices of the teeth and extended superiorly $5 \mathrm{~mm}$. A mallet and chisel were then utilized to complete the osteotomy of the lateral nasal walls and nasal septum. The entire maxilla was then down-fractured manually. Additional bone was removed with a rongeurs from the nasal septum, posterior and medial walls of the maxillary sinus and the lateral nasal wall until the maxilla could be impacted the required $5 \mathrm{~mm}$. Prior to the fixation, the occlusion was carefully checked and if needed, the maxillary position was slightly adjusted to attain maximal intercuspation. Interosseous wires were used to stabilize the maxilla in the new position. The wires were attached bilaterally at the zygomatic buttress and piriform aperture. The wounds were closed with 000 silk suture. No intermaxillary fixation was employed. The animals were returned to the recovery room awake with the nasotracheal tube in place.

Lateral cephalograms were taken in a specially constructed cephalostat so that the head position could be accurately duplicated. The monkeys had serial cephalometric x-rays taken before and after implant placement, prior 
to and just after the surgical procedure, and once a month until the time of sacrifice (Figs. 3, 4 and 5). By superimposing serial lateral cephalograms on anterior cranial base and cranial implants, the post-surgical repositioning of the maxilla and mandible in occlusion was evaluated by measuring the amount of movement of the maxillary and mandibular implants. Superimposing on maxillary implants permitted examination of changes in the positions of maxillary teeth. Similarly, by superimposing on mandibular implants changes in the position of the lower teeth were recorded! ${ }^{9}$

The three experimental monkeys were sacrificed 150 days after surgery. The two unoperated control monkeys were killed 160 days after implant placement. Prior to sacrifice, each monkey was given Ketamine and anesthetized with pentobarbital. The common carotid arteries were exposed bilaterally, cannulated, heparinized and perfused with 10 per cent buffered formalin. After decapitation, tissue blocks were cut from each monkey's head. The right mandible of all monkeys and the maxillae of one control and two experimental animals were decalcified and embedded in paraffin. Sections $7 \mu$ m thick were cut and stained with hematoxylin and eosin. The right temporomandibular joint areas of one control and two experimental monkeys were sectioned sagittally. Al1 other $H \& E$ sections were cut transversely.

During the experiment, oxytetracycline $50 \mathrm{mg} / \mathrm{kg}$ was given on specified occasions as an in vivo bone marker ${ }^{3-15}$ to aid in evaluating postsurgical repair and bony remodeling. Oxytetracycline was injected intramuscularly four days prior to surgery and four days prior to sacri- 
fice. The same injection schedule was used for control monkeys. The left mandible of all monkeys and the maxillae of the remaining one control and one experimental monkeys were embedded in Bioplastic. As part of another study, non-decalcified sections, 80-100 um thick, will be cut with a Bronwill thin sectioning machine and examined under a fluorescence microscope.

$-6-$ 
RESULTS

The animals tolerated the surgical procedure without any major post-operative complication. For six days post-surgically, they were given long-lasting penicillin (Distrycillin-procaine penicillin, 4000,000 units; dihydrostreptomycin, $0.5 \mathrm{gm}$.$) . One animal, however$ developed a nasal infection with congested breathing. The infection responded well to antibiotic therapy and was cleared up in ten days. The animals generally continued to eat normally after surgery and their initial weights of $3-4 \mathrm{~kg}$ remained stable. For ten days postsurgically the monkey chow was soaked in water before feeding.

The maxillae were mobile upon examination for three to four weeks, but after six to eight weeks there seemed to be a solid union of the osteotomized bones. Radiographically, there was evidence of primary bone bridging after one month and the surgical site was radiopaque at three months post-operatively.

The lateral cephalograms from immediately before and after surgery were traced and superimposed on anterior cranial base structures and cranial implants (Figs. 6,7 and 8). Measurements of the surgical changes were recorded, and appear in Table I. Changes in positions of the maxilla and mandible were measured by the displacement of the implants. This movement was measured parallel or perpendicular to a constructed horizontal plane (HP). The horizontal plane was drawn on the tracing paper as a line 13 degrees steeper than a line connecting anterior and posterior cranial implants. Palatal plane (PP), occlusal plane (OP) and mandibular plane (MP) changes were also measured. Figure I depicts the position of the implants and the constructed planes that were used 
to evaluate cephalometric changes.

Figure 9 shows a superimposition of cephalogram tracings demonstrating growth changes in an unoperated control monkey during the 160 day observation period. Stability of the maxillary osteotomy was measured by cranial base superimposition of the final cephalogram tracing on the x-ray taken immediately after the surgery (Figs. 10, 11 and 12). The amount of change in the craniofacial complex during this period is summarized in Table II.

After maxillary impaction, any repositioning of the teeth during the post-surgical period was also analyzed. Tracings of the maxilla and mandible were superimposed on their implants (Figs. 10,11 and 12) and changes in the position of the teeth in horizontal and vertical directions were recorded (Table III).

Cephalometric Findings. Control Animals: During a 160 day period, the control animals showed very little change. The maxilla and mandible moved downward and forward less than one $\mathrm{mm}$. The teeth showed slight amounts of extrusion and anterior migration in the bone (Table III).

Experimental Animals: The maxilla was impacted 5 to $7 \mathrm{~mm}$. in the experimental animals. This was accompanied by a decrease in facial height, a flattening of the mandibular plane angle and a more anterior positioning of the mandible relative to the maxilla. These measurements were all taken with the teeth in occlusion.

During the five month post-operative period, very small amounts of cephalometric change were observed. The maxilla did not relapse downward in any of the animals. In fact, all experimental monkeys 
showed some slight superior repositioning of the maxilla. Mandibular implants all showed less than $1 \mathrm{~mm}$. of positional change. The mandibular plane angle also showed no sign of steepening, which was consistent with the finding of no downward maxillary relapse. No consistent pattern of tooth movement after surgery could be determined. In the three individual animals, there were examples of anterior and posterior tooth movement, extrusion and intrusion.

Histological Findings. The decalcified sections of maxillae, maxillary and mandibular teeth, and temporomandibular joint of control and experimental monkeys were examined approximately five months after the surgical procedures.

The healing of the maxillae was found to be normal in all experimental animals. The osteotomy areas showed healing of the cortical bone and remodeling of the spongiosa. No areas of necrosis were found in the proximity of the osseous union of the osteotomized sites (Figs. 13 and 14). Similarly, the nasal septum, the cellular lining of maxillary sinus and midfacial sutures all appeared normal.

The periodontium of the maxillary teeth of the experimental monkeys showed no evidence of any histopathologic change, except in two monkeys where root resorption was noted at the maxillary canine apices (Fig. 15).

Since maxillary osteotomy in the present study involved 5 to $7 \mathrm{~mm}$. of superior impaction of the maxilla, a careful analysis of temporomandibular articulation of all monkeys was performed.

In the control monkeys (Figs. 16 and 17), the articular covering of the condyle was of dense fibrous tissue with a considerable number of scattered fibroblasts. The thickness of this layer was the same from the anterior to the posterior regions of the condyle. The outer 
portion of the hyaline cartilage was packed with spindle-shaped cells and, at the deeper portion, the nuclei were oval shaped and the cells had a characteristic look of chondrocytes. The chondrocytes appeared larger as they approached the medullary part of the condyle. The zone of replacement of bone was comprised of developing trabeculae and large marrow spaces.

The condylar region of all experimental animals (Figs. 18 and 19) showed a varied histological picture as compared to the controls. The fibrous articular covering was found to be very thin. The fibrous layer was not uniformly thick over the length of the articular surface, the anterior region having a very thin layer. Very few scattered fibroblasts were present in this layer and the majority of the cells were lined at the surface facing the articular disc. The proliferative zone and the zone of hypertrophy of condylar cartilage had fewer cells as compared to controls.

The condylar cartilage in the posterior region was relatively more active than in the middle and anterior regions. Very few marrow spaces and developing trabeculae were found under the cartilagious zone. The bone in this area also appeared relatively mature.

The articular disc (Fig. 20) of the control animals had many fibroblasts and few mesenchymal cells. The fibers of the disc were densely packed. The disc was relatively thick in the posterior region, and was narrowest in the anteromedial part. Anteriorly, the fibers of the disc were continuous with fibers of the lateral pterygoid muscle. No chondrocytes were found in the articular disc.

The articular disc (Fig. 21) of experimental animals was approxi- 
mately two to three times thicker than the control animals. The fiber bundles were densely packed in the anterior and posterior regions, whereas in the middle region they were loose.

The temporal surface of the temporomandibular joint (Figs. 16 and 22) had a thin fibrous layer of uniform thickness from the anterior to the posterior region. Scattered fibroblasts as well as chondrocytes were found in this layer. The bony area under the fibrous layer had a large number of small marrow spaces and areas of new bone formation.

The fibrous layer on the articular fossa of the temporal bone of the experimental animals was found to be very thin in the middle and anterior region (Figs. 18 and 23 ) and in some areas of the middle region was almost non-existant. In the posterior region, the fibrous layer was present, but no uniform thickness was evident in the serial sections. In this region, evidence of new bone formation was present as seen from the resting lines. The bone lying immediately under the fibrous layer appeared mature and almost devoid of marrow spaces. 


\section{DISCUSSION}

The present study successfully tried to simulate a surgical procedure commonly used to correct dentofacial abnormalities. A 5 to $7 \mathrm{~mm}$. superior impaction of the maxilla by surgical osteotomy was attained without any major post-operative complications. The procedure proved to be very stable by cephalometric and clinical evaluation. The slight repositioning of the maxilla during the five month post-surgical period was in a superior direction. This finding is consistent with the results of Schendel et a1 ${ }^{3.1}$, who reported on the post-operative changes in the position of the maxilla of patients after maxillary osteotomies. The small random movements of various teeth observed during the postsurgical period were mainly due to settling of the occlusion.

Histological examination of the maxilla showed an osseous union between the osteotomized parts of bone. These findings support the results of Bel14-5 who studied revascularization and bone healing after anterior and posterior maxillary osteotomies. He reported that intraosseous and intrapulpal circulation was maintained after the surgery and healing was by osseous union within six weeks. The results of this study agree with the conclusions of Bell, that the maxillary osteotomy procedures are biologically sound.

On the other hand, no study in the literature has reported the effect of maxillary osteotomies on the temporomandibular joint. Since 5 to $7 \mathrm{~mm}$. of superior maxillary impaction, as done in the present study, is common in clinical maxillary osteotomies, it invariably causes an overclosure of the mandible if occlusion is maintained 
during surgery. As shown with cephalometric results, the mandible of the experimental monkeys displaced upward and forward in a counterclockwise motion after maxillary osteotomy. This altered motion of the mandible during function might have resulted in the histologic changes seen in the temporomandibular joints of the experimental monkeys.

Since any change in the temporomandibular joint will be of an adaptive nature due to possible functional alteration, the results of the present study can be compared with studies where extraoral force was applied to maxillary and mandibular teeth, or where the vertical dimension of the face was altered by experimental means.

One method used for decreasing the vertical dimension of experimental animals used in the past has been by selective extraction of the maxillary and mandibular teeth. The majority of these studies were done on rats and results showed fibrosis in the anterior portion of the condyle affecting subchondral bone, hematopoietic marrow spaces and cartilage cap and loosening and fraying of the articular disc." Furstman $^{16}$ extracted one, two or four quadrants of the molar teeth of rats and studied them two, four and six months after the surgical procedures. He reported an increase in the thickness of the articular disc and thinning of the cartilaginous cap of the condyles.

The results of the present study confirm the findings of all these investigators. The experimental monkeys in the present study five months post-operatively, showed a markedly thinner cartilaginous cap and thick articular disc. However, the results disagree with the observation of Furstman that the squamosal portion of the joint had a thick 
fibrous connective tissue layer. In the present study, the fibrous layer of the articular fossa was found to be very thin. This difference in results can be due to numerous factors such as differences in the species of animals, age of the animals, and types of procedures performed in the two studies. The studies using rats also failed to mention the amount of overclosure or rotation of mandible affected by their procedures.

Another experimental procedure used in the literature to study adaptive changes in the temporomandibular joint has been by changing the horizontal or vertical position of the mandible using occlusal splints. ${ }^{3,8,9,10}$ Ramfjord and Hiniker ${ }^{29}$ and Ramfjord and Enlow ${ }^{28}$ studied the effect of anterior displacement of the mandible $(1.5 \mathrm{~mm}$.) on temporomandibular joints of adult rhesus monkeys. In their short term experiments they found insignificant adaptive changes in the temporomandibular joints. In the long-term studies, where animals were sacrificed 1.5, 2 and 3 years after the start of displacement, no adaptive changes were found. They concluded that in 10-15 year old adult animals, the temporomandibular joint is stable and resistant to occlusal change. Similar conclusions were made by McNamara 20 who used 6-7 year old adult monkeys. The results of the present study differ from their conclusions, possibly because of the different nature of the mandibular displacement and probably because of the age of the monkeys. In the present study, the monkeys were determined to be young adults, as the third molars were not yet in occlusion and occlusal wear of the teeth was minimal.

Stockli and Willert ${ }^{32}$ also studied tissue reactions in the temporomandibular joints after anterior displacement of the mandible in 
growing Macaca irus monkeys. They reported marked enlargement of the condylar cartilage in the posterior region after 201 days of experimental period. No regressive changes were noted in three months after the removal of the appliance. In a similar study on juvenile rhesus monkeys, McNamara ${ }^{20}$ did not find any histologic evidence of experimentally induced tissue response. He postulated that adaptive processes might have been of such nature thiat they could not be differentiated from normal growth. In these studies the mandible was brought forward, which restricted certain movements of the mandible. In the present study the mandible was unrestrained but was forced to overclose in a counterclockwise fashion only during functional movements. This was probably the main cause of atrophic temporomandibular joint changes found in the present study.

McNamara ${ }^{20}$ cited his unpublished work in which monkeys were rendered edentulous. He reported that the lateral head of the pterygoid became hyperactive in these animals. He further added that in monkeys the superior head of the lateral pterygoid muscle acted in stabilizing the articular disc and condylar head during normal closing movements. The thickening of the articular disc found in the experimental animals thus could have been caused by hyperactivity of the lateral pterygoid muscle.

The articular fossa of the temporal bone also showed extensive changes such as thin or missing fibrous layer in the middle and anterior region. It is possible that during the altered functional movements of the mandible in the experimental animals these areas had the least functional stimulation. Cephalometric and histologic analys is of the experimental animals also indicated that, with overclosure of the 
mandible, the condyle probably displaced posteriorly in the fossa.

The changes seen in the condylar region of the experimental animals were the most bewijdering. As compared to controls, the cartilage appeared atrophic and showed considerable aging. Contrary to the belief that increased function will cause stimulatory growth of the condyle, $9.90,254$ the zone of bone replacement of cartilage showed mostly mature bone and lack of marrow spaces. Since the animals in the present study were not histologically examined at a short duration after the surgery, it is difficult to speculate the sequence of changes which might have occurred prior to the histologic picture seen five months after surgery. Since the changes were not limited to cartilage only, they can not be summarily dismissed as due to normal aging process.

The results of the present study indicate that although experimental maxillary osteotomy procedures heal by osseous process with normal revascularization of the surgical sites and teeth ${ }^{4}$, extensive adaptive changes take place in the temporomandibular joint. Almost no long-term clinical data is available where a concerted effort has been made to study the changes, if any, in the temporomandibular joints after the maxillary osteotomy procedures. Further experiments are needed to study changes in neuromuscular behavior and its effects on the rest position of the mandible, and also to investigate physiologicmorphologic adaptive changes at the temporomandibular articulation at various times after surgery. 
SUMMARY AND CONCLUSION

Five Macaca irus monkeys were used in this study to determine cephalometric and histologic changes after total maxillary impactions. In the three experimental animals, the maxilla was impacted 5-7 mm., and lateral cephalograms were taken over a 150 day period. By superimposing on craniofacial implants, osseous and dental changes were measured. Excellent skeletal stability was demonstrated during the post-operative period.

Histologically, there was normal osseous healing of the osteotomized maxillae. Accompanying the counterclockwise rotation (overclosure) of the mandible, there was extensive change in the temporomandibular joint. In the experimental monkeys, the fibrous articular covering of the temporal fossa was thin and irregular. The condylar cartilage appeared atrophic and showed considerable aging. Also, the articular disc was much thicker in the experimental animals.

The study showed the total maxillary osteotomy to be a stable procedure after 150 days of post-operative observation. However, further studies are needed to investigate the neuromuscular and adaptive response of temporomandibular articulation and mandibular rest position after maxillary surgical procedures. 


\section{REFERENCES}

1. Anderson, B.G., Smith, A.H., Arnim, S.S., and Orten, A.V.: Changes in molar teeth and their supporting structure of rats following extraction of upper right first and second molars, Yale J. Biol. and Med. 9:189, 1936.

2. Avant, F.G., Averi11, C.J., and Hahn, W.E.: Changes in the temporomandibular joint of rats caused by alterations in the intermaxillary relationship of the teeth, J.D. Res. 31:500, 1952.

3. Baume, L.J., and Derichsweiler, H.: Is the condylar growth center responsive to orthodontic therapy? Oral Surg., Oral Med. and Oral Path. 14:347, 1961.

4. Bell, W.H.: Revascularization and bone healing after anterior maxillary osteotomy: A study using adult rhesus monkeys, J. Oral Surg. 27:249-255, 1969.

5. Bell, W.H.: Biologic basis for maxillary osteotomies, Am. J. Anthrop. 38:279-289, 1973 .

6. Bjork, A.: Facial growth in man studied with the aid of metallic implants, Acta Odont. Scand. 13:9-34, 1955.

7. Bjork, A.: The use of metallic implants in the study of facial growth in children. Method and application, Amer. J. Phys. Anthrop. 29:243-254, 1968.

8. Breitner, C.: Bone changes resulting from experimental orthodontic treatment, Am. J. Orthodontics and Oral Surg. 26:521, 1940.

9. Charlier, J.P.: Les facteurs mécanique dans la croissance de 7 'arc basal mandibulaire \& la lumiere de 1 'analyse des caracteres structuraux et des proprietes biologique de cartilage condylien, Orthod. Franç 38:177-186, 1967.

10. Charlier, J.P., Petrovic, A., and Hermann-Stutzmann, J.: Effects of mandibular hyperpropulsion on the prechondroblastic zone of young rat condyle, Amer. J. Orthod. 55:71-74, 1969

11. Cimasoni, G.: Histopathology of the temporomandibular joint following bilateral extractions of molars in the rat, Oral Surg., Oral Med. and Oral Path. 16:613-621, 1963.

12. Cimasoni, G., and Becks, H.: Growth study of the rat mandible as related to function, Angle Orthodontist 33:27, 1963. 
13. Cleal1, J.F., Perkins, R.E., and Giloa, J.E.: Bone marking agents for the longitudinal study of growth in animals, Archs. Oral Biol. 9:627-646, 1964.

14. Frost, H.M.: Tetracycline bone labeling in anatomy, Amer. J. Phys. Anthrop. 29:183-196, 1968.

15. Frost, H.M.: Tetracycline-based histological analysis of bone remodeling, Cal. Tiss. Res. 3:211-237, 1969.

16. Furstman, L.: The effect of loss of occlusion upon the mandibular joint, Amer. J. Orthod. $51: 245-261,1965$.

17. Hurme, V., and Van Waganen, G.,: Basic data on the emergence of permanent teeth in the rhesus monkey, Proc. Amer. Philo, Soc. 105:105-140, 1961.

18. K४le, H.: Surgical operations on the alveolar ridge to correct occlusal abnormalities, Oral Surg. 12:515, 1959.

19. McNamara, J.A.: Neuromuscular and skeletal adaptations to altered orofacial function, Monograph Number 1, 1972.

20. McNamara, J.A.Jr., : Neuromuscular and skeletal adaptations to altered function in the orofacial region, Amer. J. Orthod. 64: 578-606, 1973.

21. McNei1, R.W., Hooley, J.R., and Sundberg, R.W., Skeletal relapse during intermaxillary fixation, J. Oral. Surg. 31:212-227, 1973.

22. Mohnac, A.M.: Surgical correction of maxilla-mandibular deformities, J. Oral Surg. 23:393-407, 1965.

23. Murphey, P.J., and Walker, R.V.: Correction of maxillary protrusion by ostectomy and orthodontic therapy, J. Oral Surg., Anesth., Hosp. Dent. Serv. 21:275-290, 1963.

24. Obwegeser, H.: American Society of Oral Surgery Comprehensive Conference on oral surgery, Walter Reed Army Medical Center, Washington, D.C., June 20, 1966.

25. Petrovic, M.A., and Stutzmann, J.: Le muscle ptérygoldien externe et 1 a crol ssance du condyle mandibulaire; recherches experimentales chez le jeune rat, Orthod. Franç, 43:271-285, 1962.

26. Poulton, D.R. and Ware, W.H.: Surgical-orthodontic treatment of severe mandibular retrusion, Amer. J. Orthod. 59:244-265, 1971.

27. Poulton, D.R. and Ware, W.H.: Surgical-orthodontic treatment of severe mandibular retrusion (Part II), Amer. J. Orthod. 63:237-255, 1974.

28. Ramfjord, S.D., and Enlow, R.D.: Anterior displacement of the mandible in adult rhesus monkeys: long term observations, J. Prosthet. Dent. 26:517-531, 1971 . 
29. Ramfjord, S.D., and Hiniker, J.J.: Distal displacement of the mandible in adult rhesus monkeys, J. Prosth. Dent. 16:491-502, 1966.

30. Sarnat, B.G.: Growth of bones as revealed by implant markers in animals, Amer. J. Phys. Antrop. 29:255-286, 1968.

31. Schendel, S.A., Eisenfeld, J.H., Bell, W.H., and Epker, B.N.: Superior repositioning of the maxilla: stability and soft tissue osseous relations, Am. J. Orthod. 70:663-674, 1976.

32. Stocki, P.W. and Willert, H.G.: Tissue reactions in the temporomandibular joint resulting from anterior displacement of the mandible in the monkey, Amer. J. Orthod. 60:142-155, 1971.

33. Stoker, N.G. and Epker, B.N.: The posterior maxillary ostectomy: a retrospective study of treatment results, Int. J. Oral Surg. 3:153-157, 1974 .

34. Voget, G., and Pignanel1i, M.: Indagini istochimiche sult articolozione T.M. del Macacus rehesus in corso di trattamento gnato-ortopedica, Rass. Int. Stomatol Prat. 9:46-50, Supp.4, 1958.

35. Willmar, K.: On Lefort I osteotomy. Scand. J. Plast. Reconst. Surg., Supplement 12, 1-65, 1974.

36. Young, R.A. and Epker, B.N.: The anterior maxillary osteotomy: a retrospective evaluation of sinus health, patient acceptance and relapse, J. Oral Surg. 30:69-72, 1972. 


\section{LEGENDS}

Figure 1 - Tracing of a cephalogram showing the positions of implants and constructed planes (HP, horizontal plane; PP, palatal plane; OP, occlusal plane; MP, mandibular plane).

Figure 2 - Diagrammatic representation of a monkey skull indicating the osteotomy site. The maxillary third molars were extracted.

Figure 3 - Cephalogram of an experimental monkey (C-4) prior to the maxillary osteotomy. Note the position of metallic implants. The implant lying in the lower lip was not used for measurement purposes.

Figure 4 - Cephalogram of C-4 immediately after maxillary osteotomy. The maxillary second molar was extracted in this monkey. The maxilla was fixed by intraosseous wiring.

Figure 5 - Cephalogram of C-4, 150 days after surgery. Note the teeth are in occlusion and the opaque area of new bone formation at the osteotomy site. The maxillary and nasal bone areas have also remodelled.

Figures 6-8 - Lateral cephalogram tracings of monkeys C-3, C-4, and C-6, showing skeletal changes produced by the total maxillary osteotomy. The interrupted lines represent the post-surgical cephalogram. Tracings are superimposed on anterior cranial base structures and cranial implants. The amount of impaction in the three monkeys ranged from 5 to $7 \mathrm{~mm}$. 
Figure 9. - Lateral cephalogram tracings of control monkey C-5. The dotted line represents 160 days after the start of the experimental period shown by the solid line. Clockwise from the top, the overlay tracings are superimposed on cranial base, mandibular and maxillary implants. Very small increments of mandibular growth and tooth movement were noted.

Figures 10-12 - Tracings of lateral cephalograms of monkeys C-3, C-4, and C-6 demonstrating changes during the post-operative period. Interrupted lines represent the cephalograms taken 150 days after surgery. Very small amounts of skeletal change, mandibular growth and random tooth movement can be seen.

Figures 13 and 14 - Histologic appearancs of the osteotomy site 150 days after surgery. The new bone is calcified and appears highly vascularized as indicated by the large number of marrow spaces. H.E $\times 125$

Figure 15 - Area of canine root apex (A) of an experimental animal 150 days post-surgical showing root resorption (R). H.E $\times 125$

Figure 16 - Temporomandibular joint of a control monkey. Condylar cartilage (cc), articular disc (ad) and temporal surface (ts), H.E $\times 15$

Figure 17 - The condylar cartilage of a control monkey showing A) articular surface, B) proliferative zone, C) zone of hypertrophy, D) area of endochondral bone formation. H.E $\times 125$ 
Figure 18 - Temporomandibular joint of an experimental monkey, 150 days after the maxillary osteotomy. Note the condylar cartilage (cc) is not very active, especially in the anterior region of the condyle, and the thickened articular disc (ad). The temporal surface (ts) is almost devoid of fibers on the articular surface, especially in the middle region. H.E $\times 15$

Figure 19 - The condylar cartilage of an experimental monkey. Note fewer cells in the articular surface (A). The proliferative zone (B) is 4 to 5 cell layers thick but has considerably decreased number of cells in the zone of hypertrophy (C). H,E $\times 125$

Figure 20 - Higher magnification of the temporomandibular joint articulation in the middle region of a control monkey. Temporal surface (ts), articular disc (ad) and condylar cartilage (cc). H.E $\times 125$

Figure 21 - Higher magnification of temporomandibular joint articulation in the anterior region of an experimental monkey. Note decreased activity of condylar cartilage (cc) and thickened articular disc (ad). H.E $\times 50$

Figure 22 - Higher magnification of the temporal surface (ts) of temporomandibular joint of a control monkey in the middle region. . Note the fibrous layer and large number of fibroblasts. H.E $\times 125$

Figure 23 - Higher magnification of temporal surface (ts) of temporomandibular joint of an experimental monkey. Note the lack of fibrous Tayer, presence of scattered fibroblasts and chondrocytes. H.E $\times 125$ 
Fig. 1

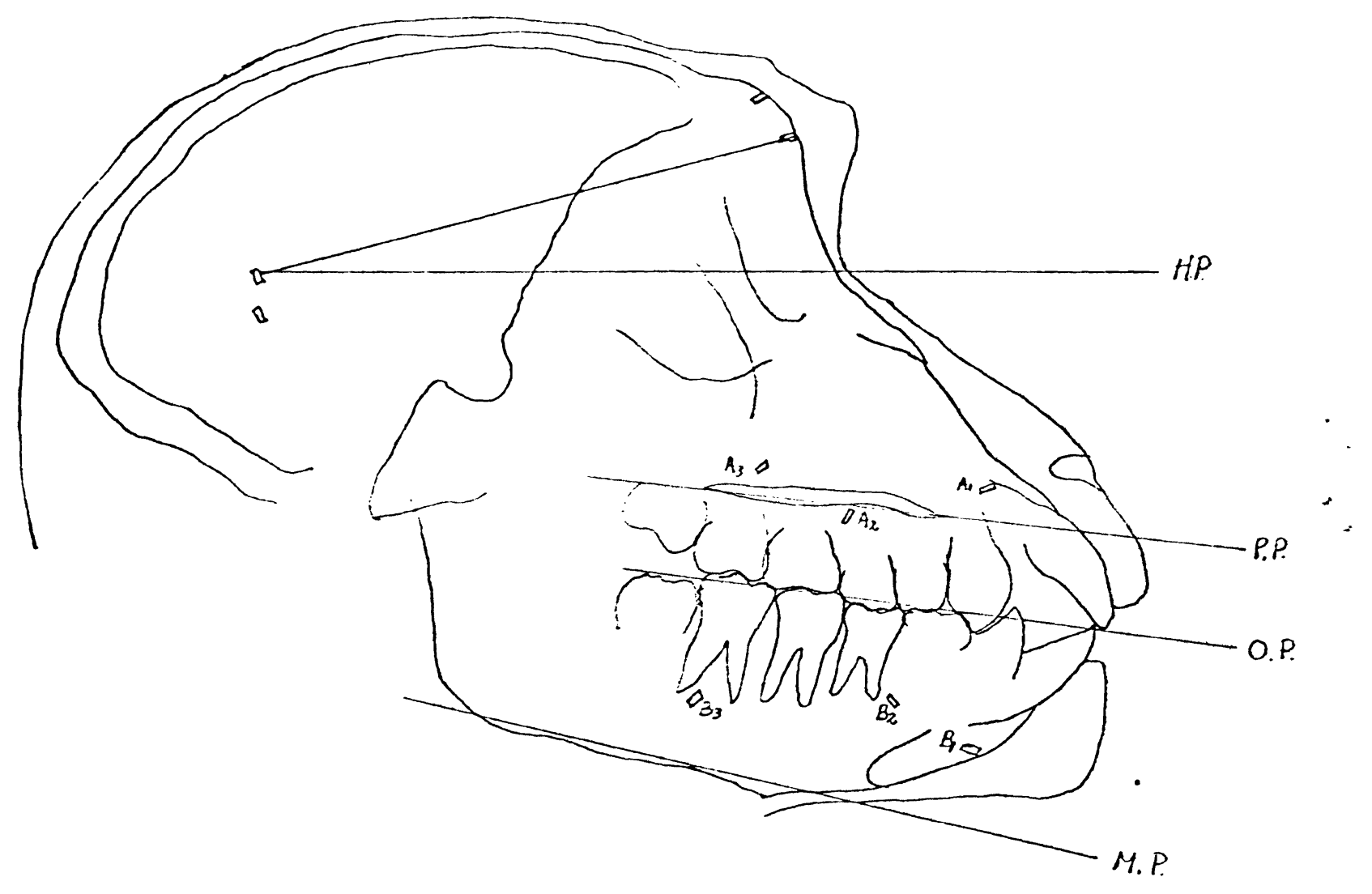


Fig. 2

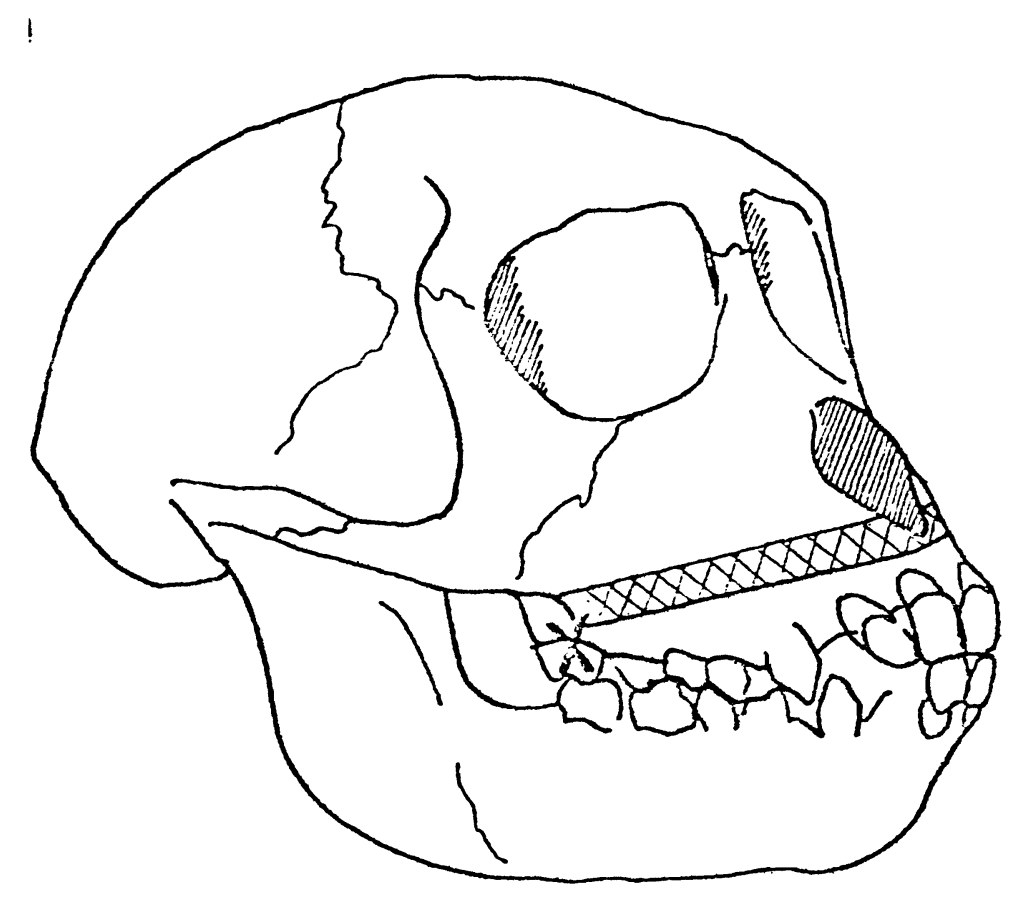


Fig. 3

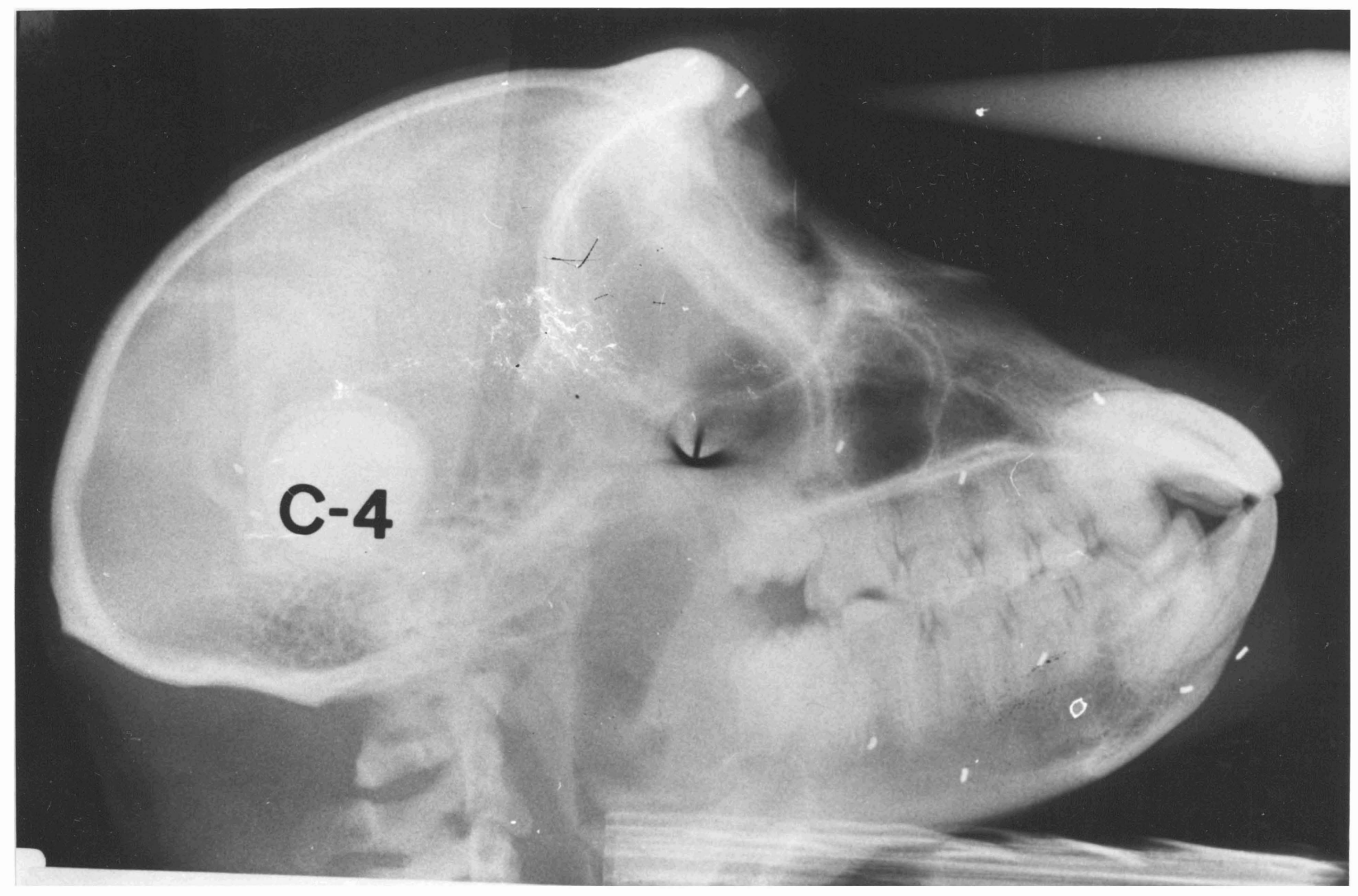


Fig. 4

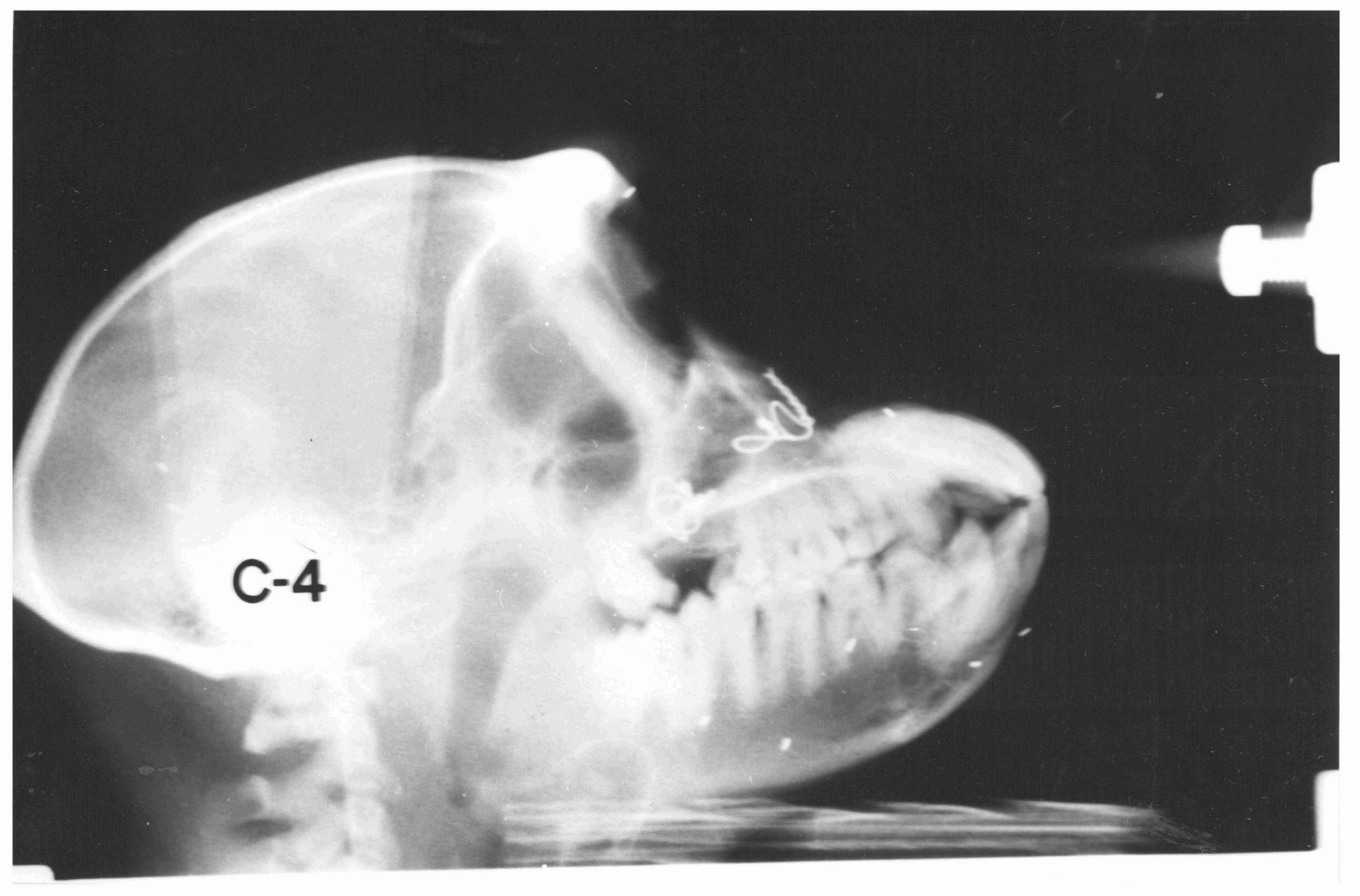


Fig. 5

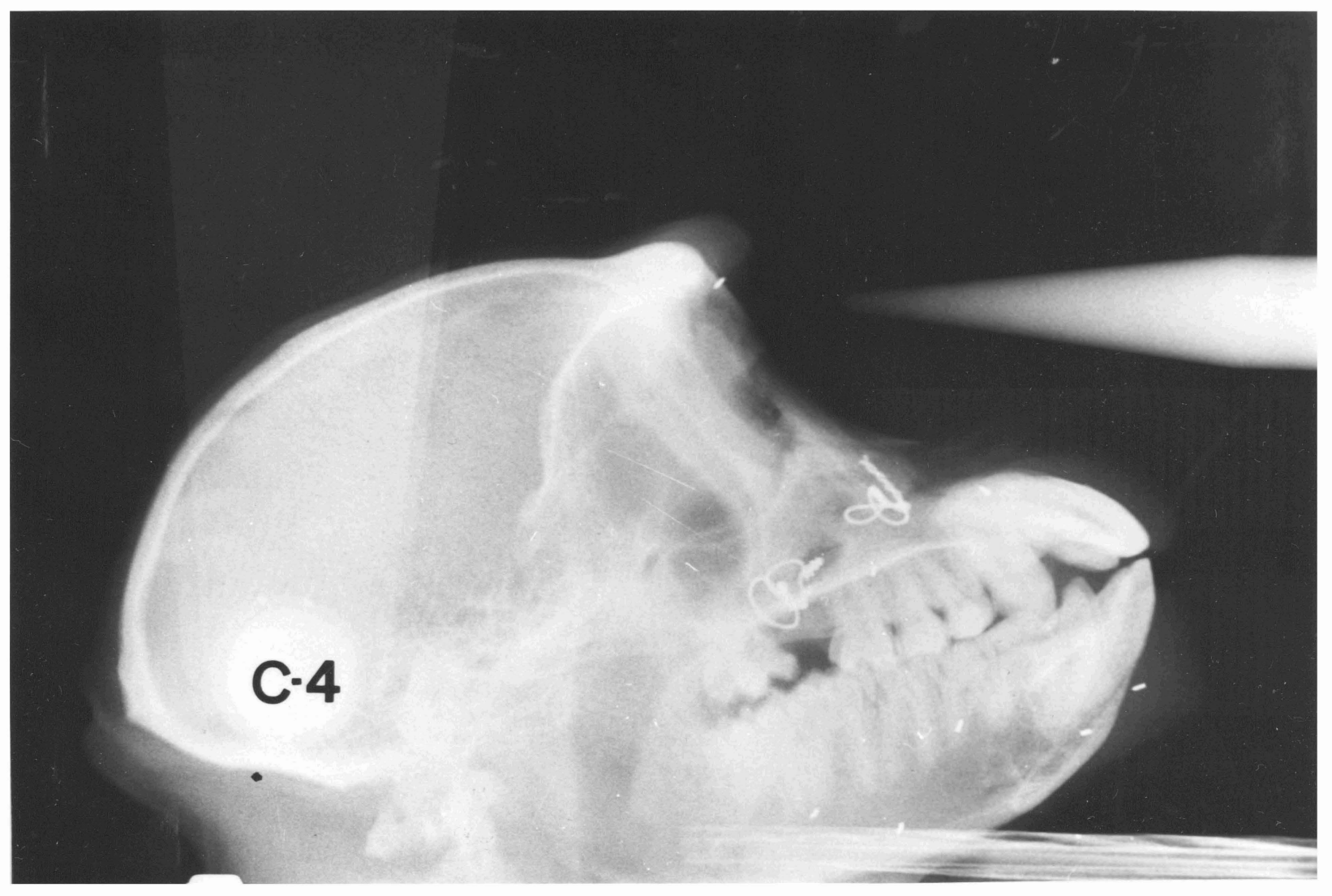


C -3

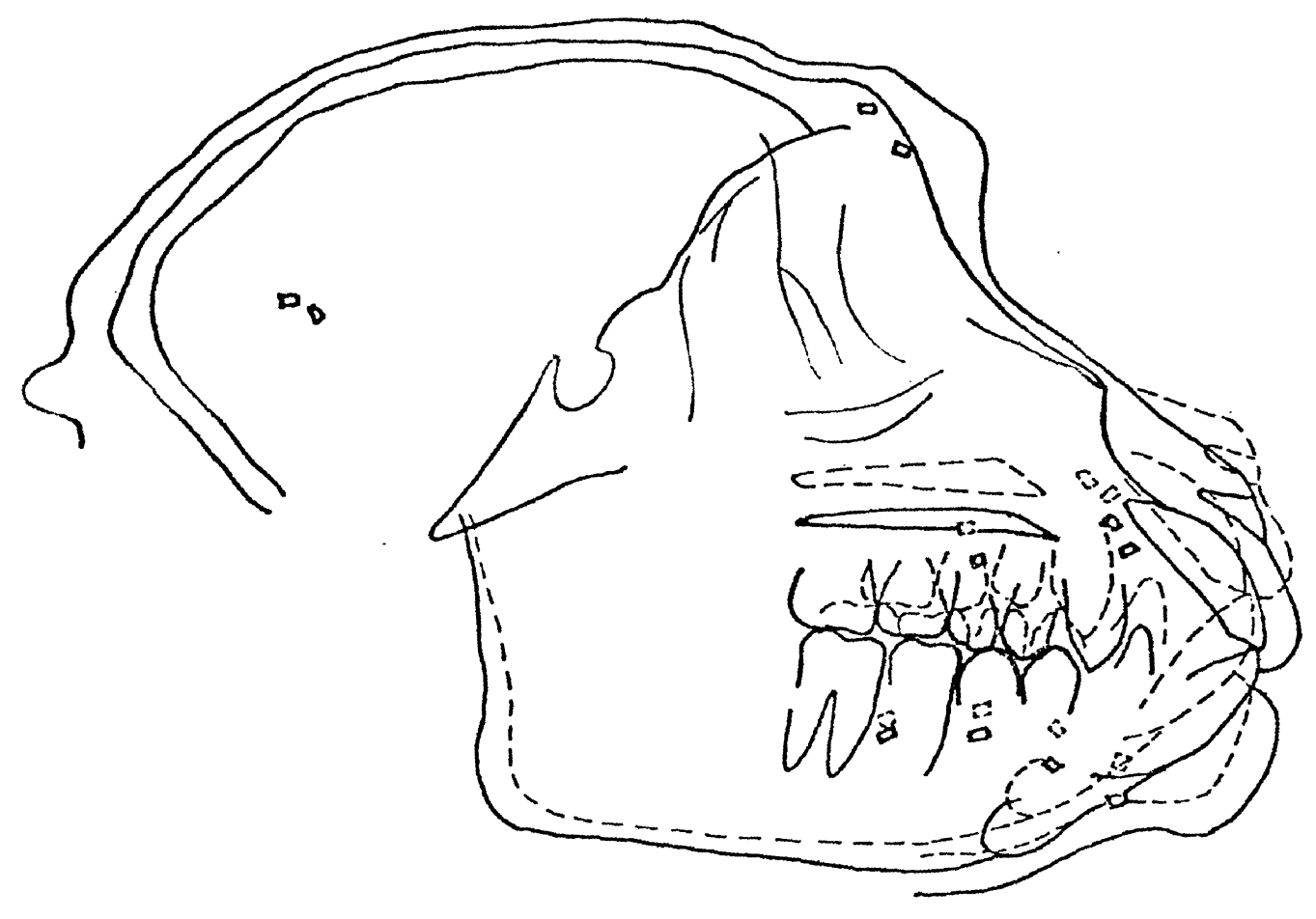

Fig. 6 
$C-4$

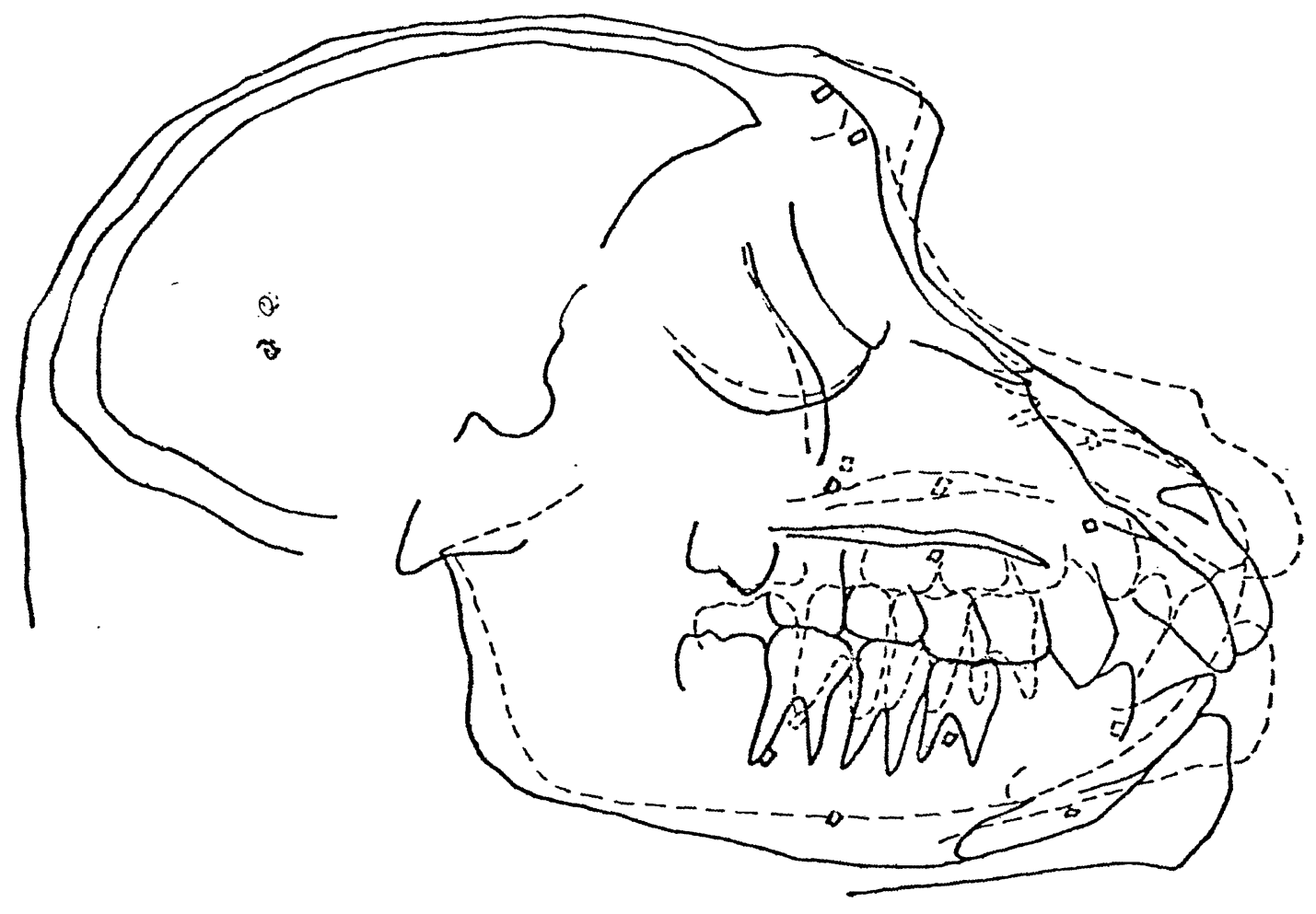

Eig. 7 
$c-6$

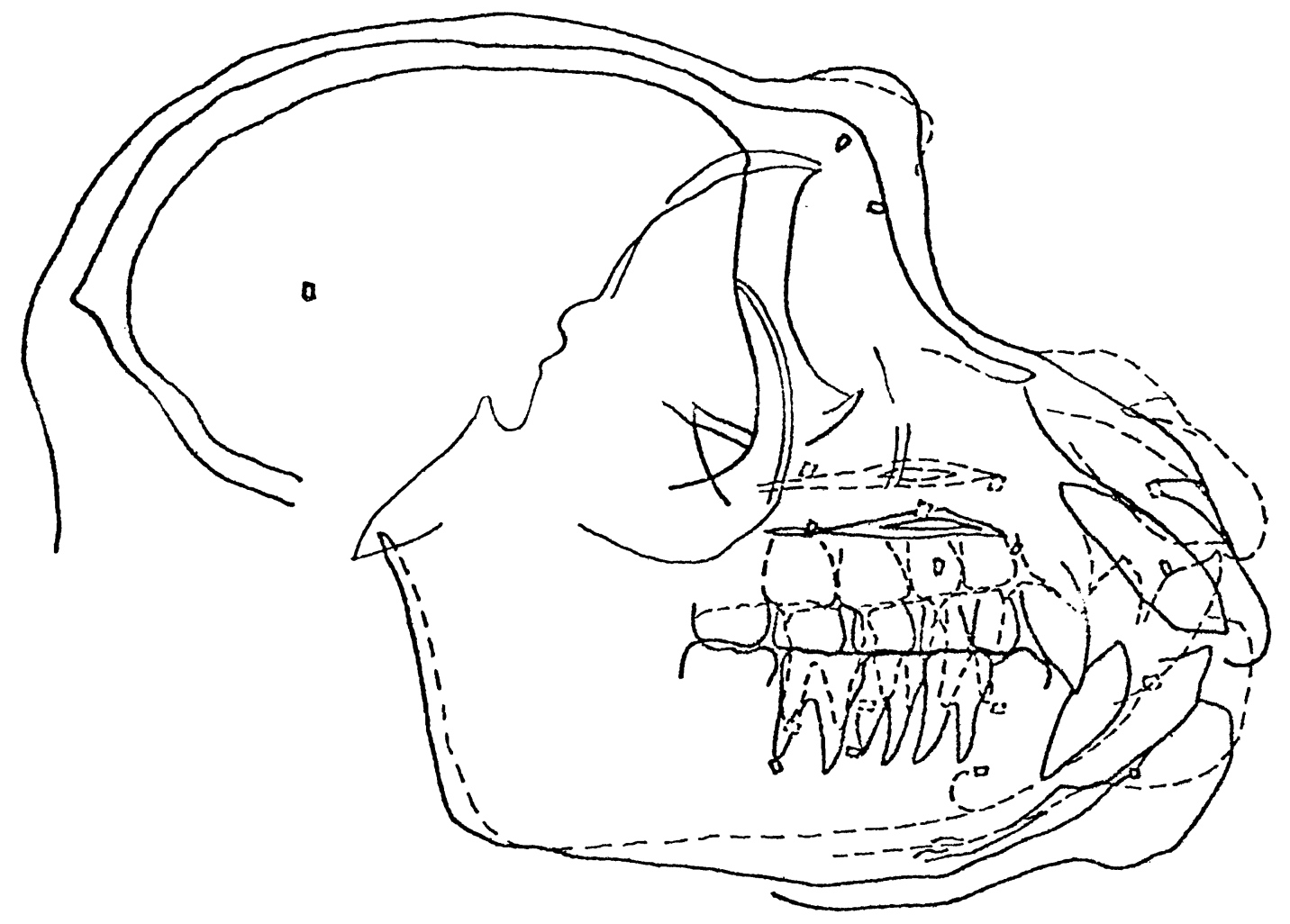

Fig. 8 


\section{$C-5$}
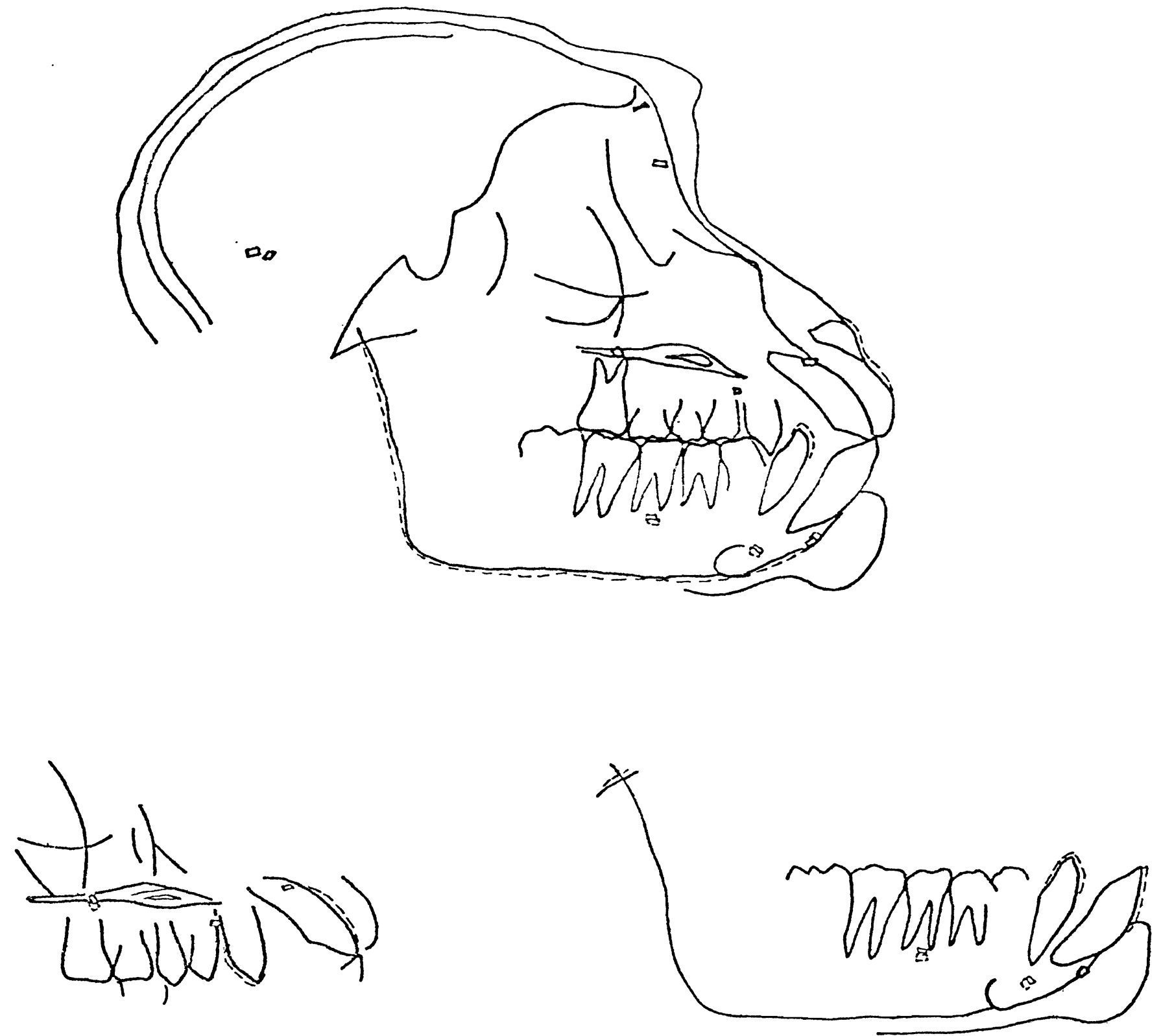

Fig. 9 
$C-3$
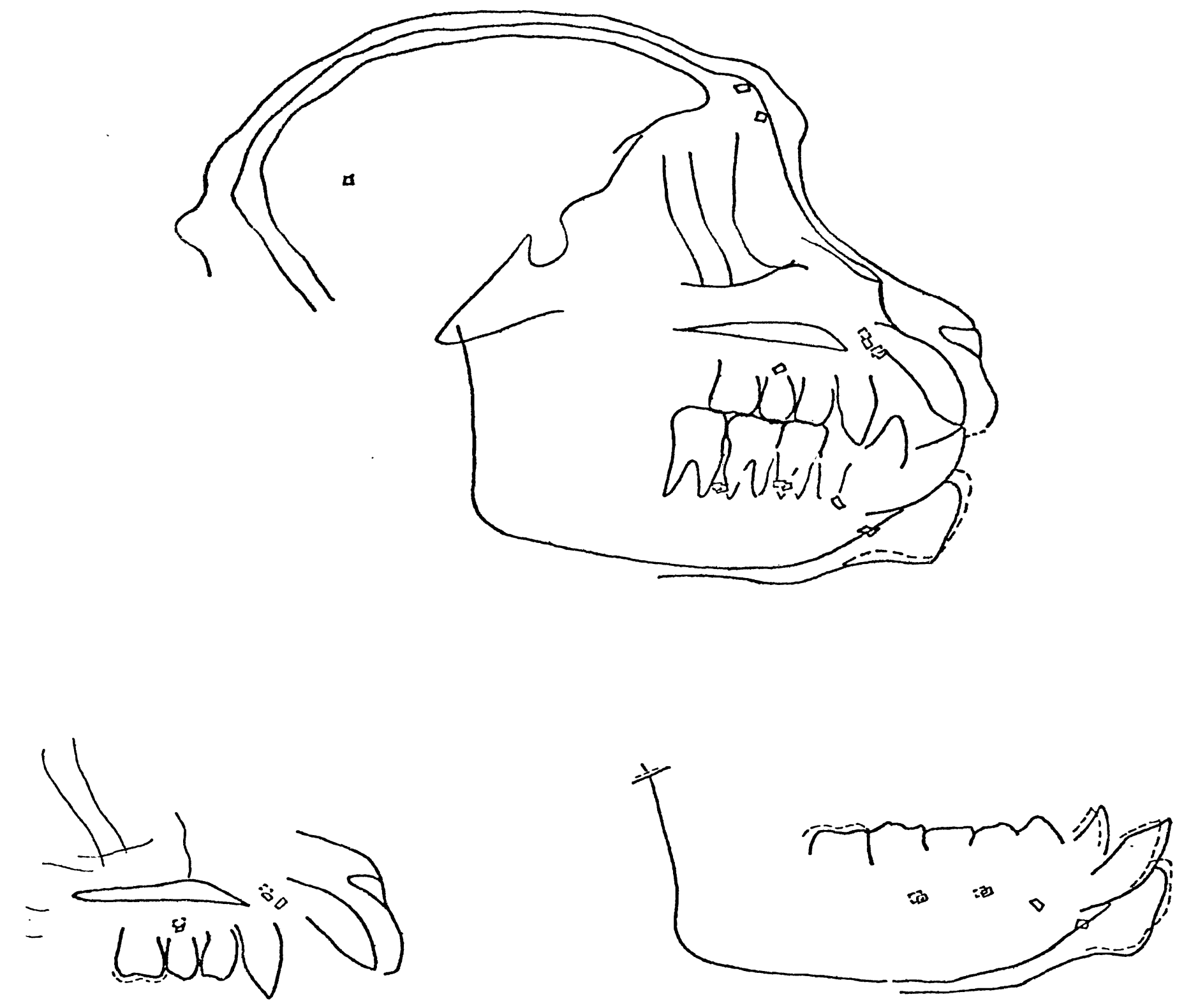

Fig. 10 
$C-4$
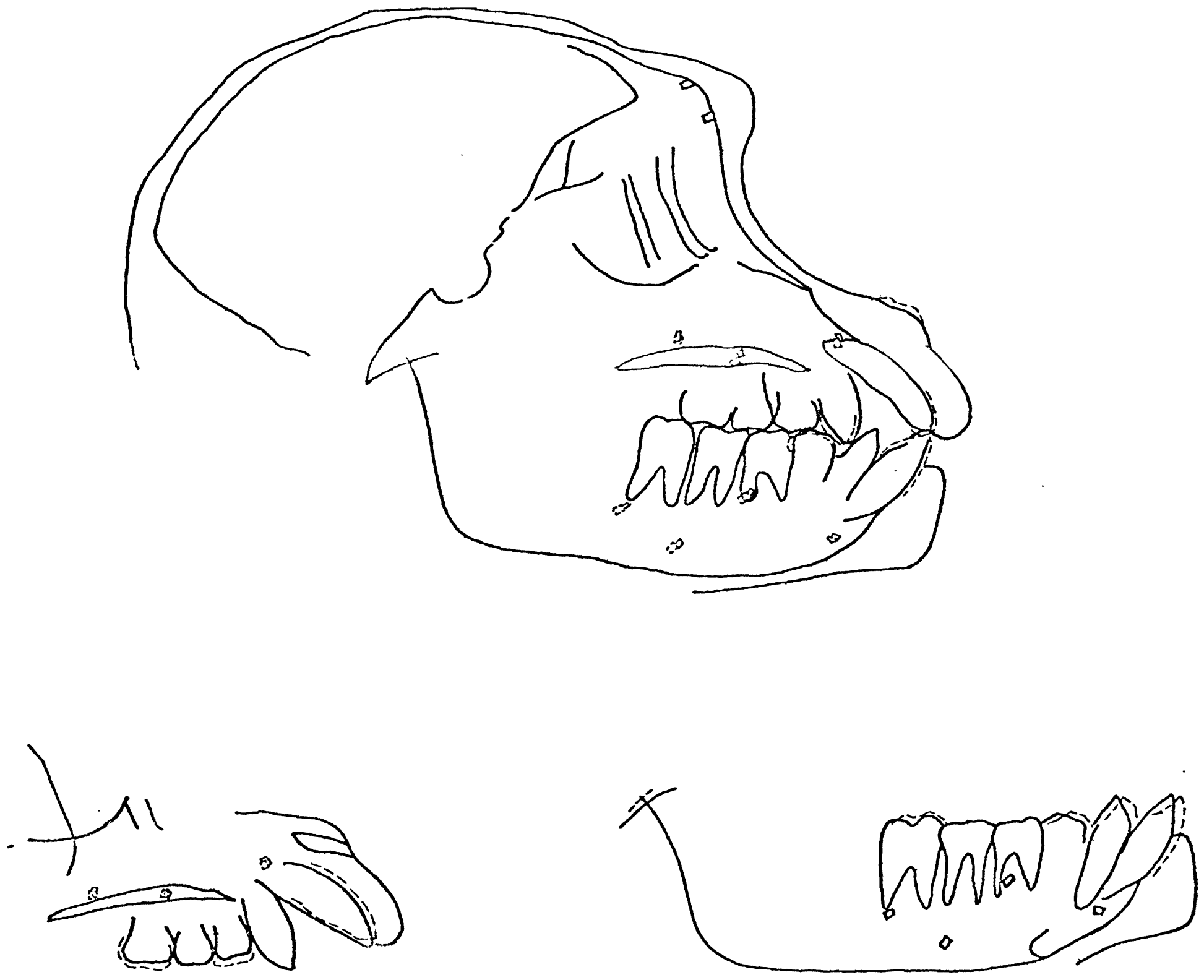

Fig. 11 

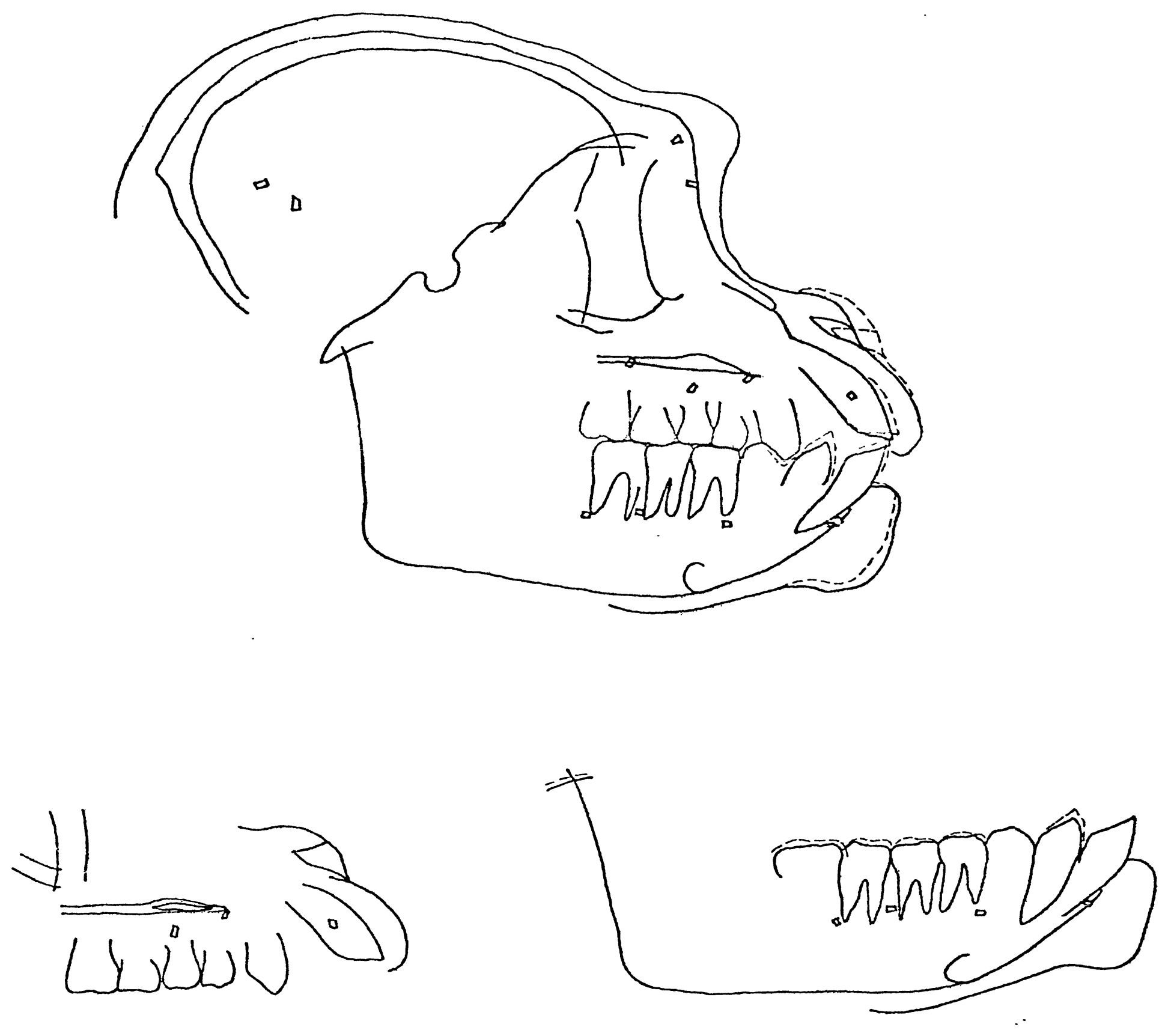


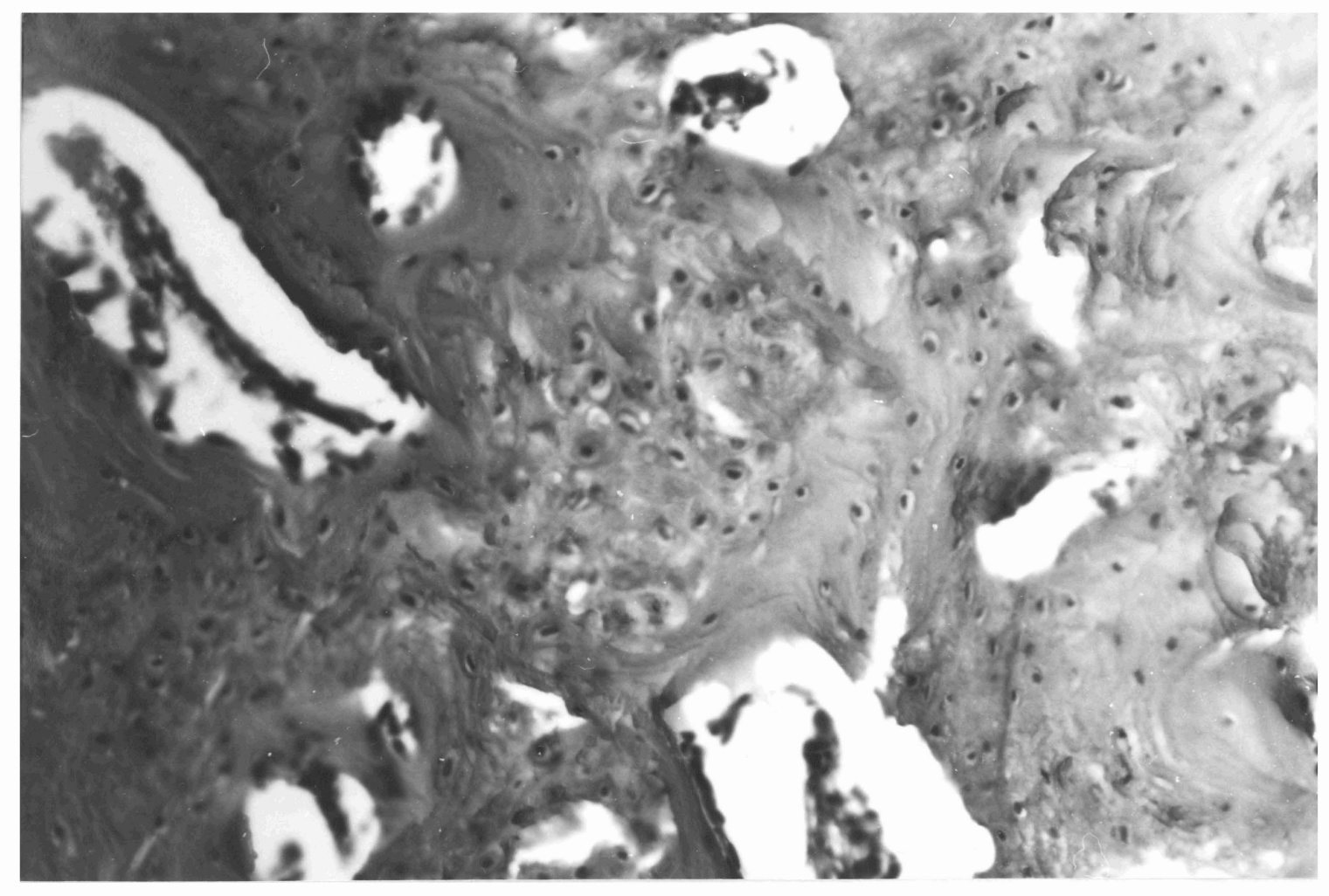

Fig. 13

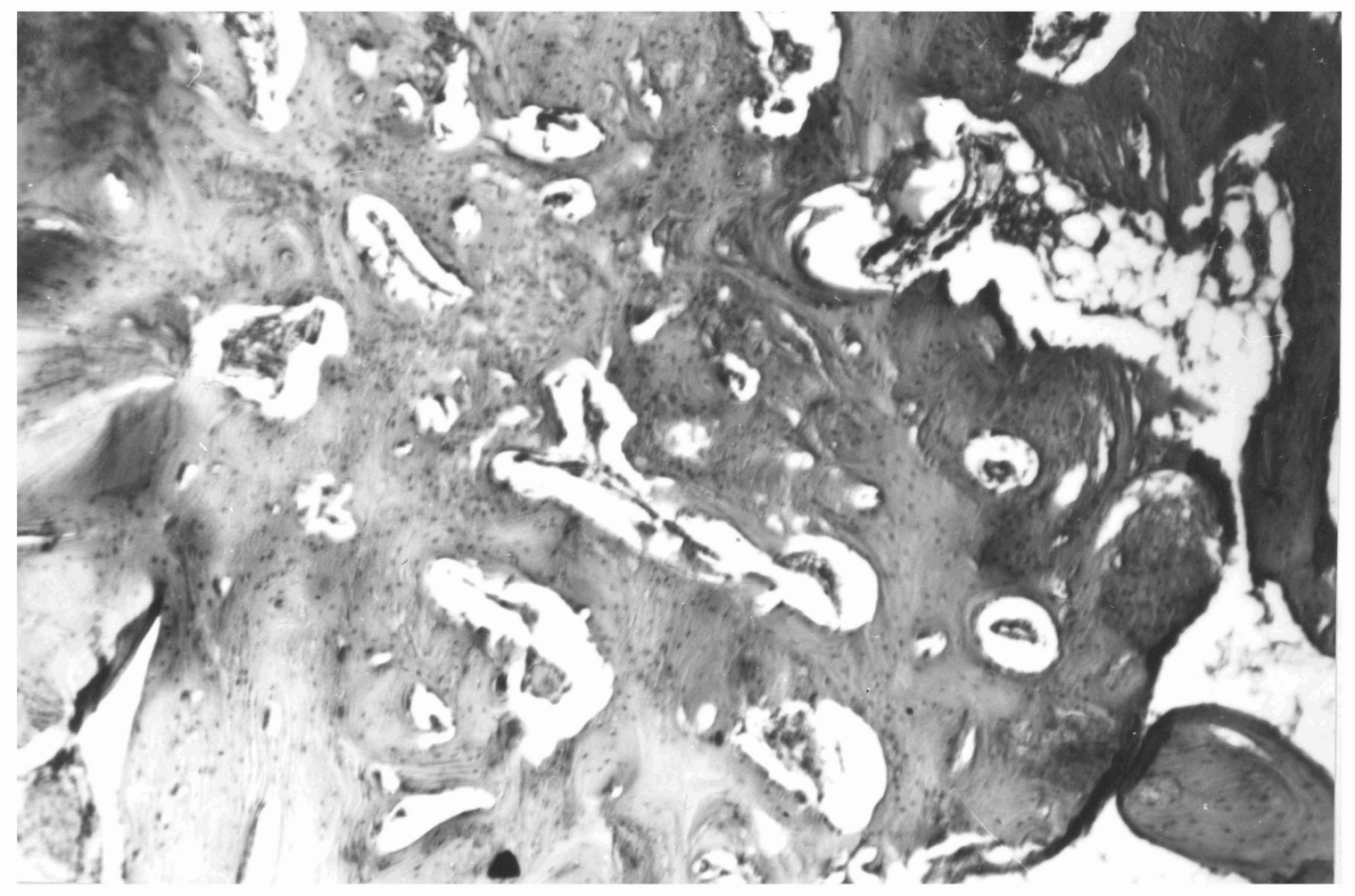




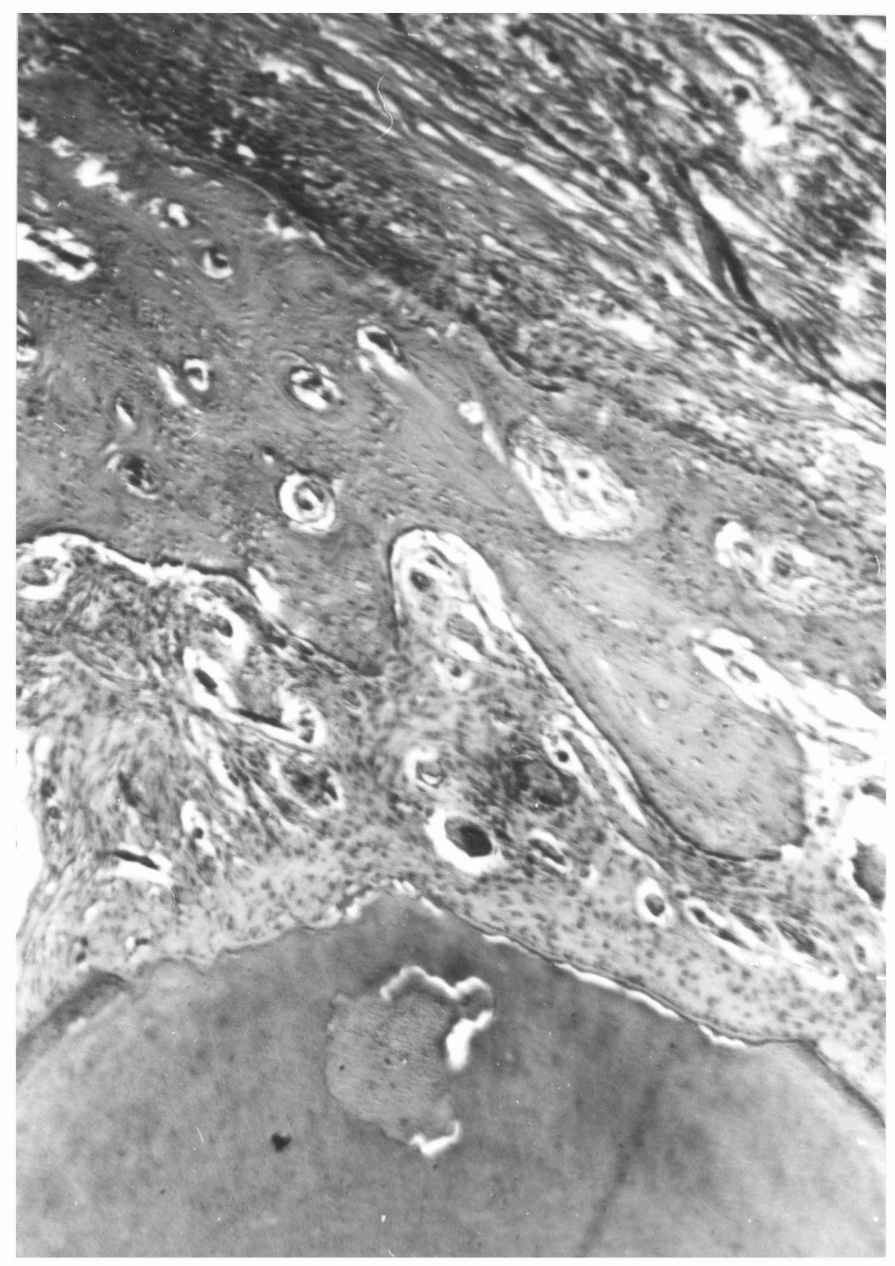

Fig. 15

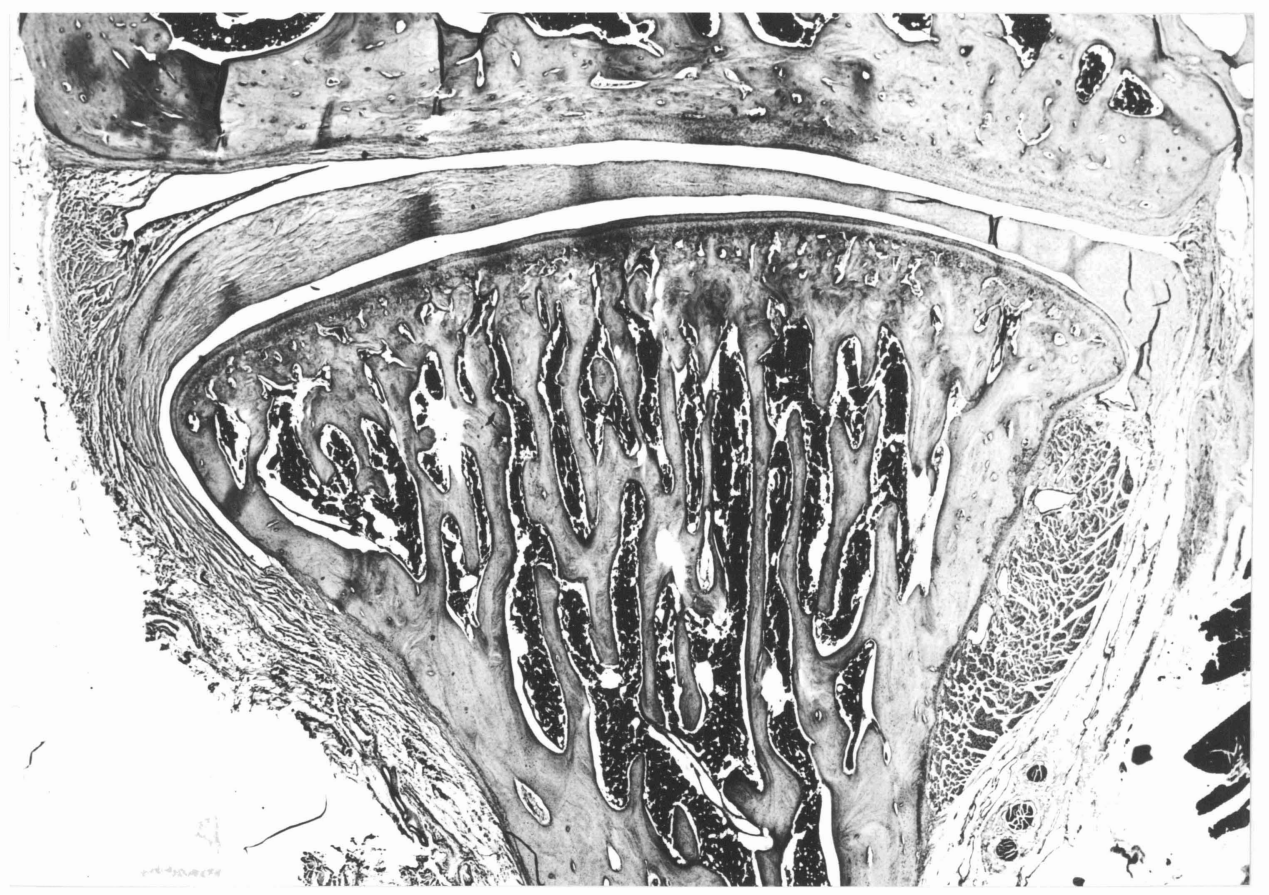

Fig. 16 


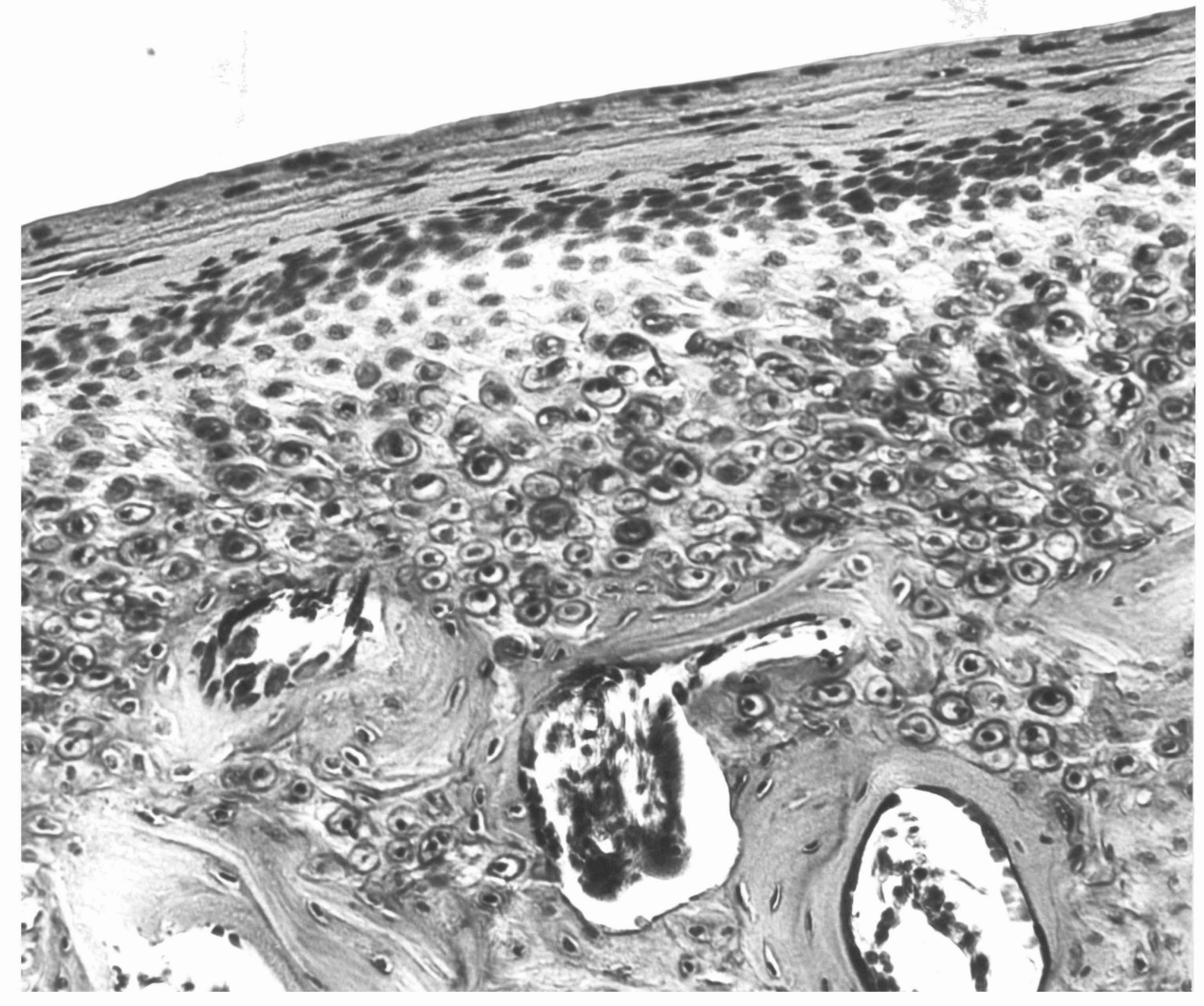

Fig. 17

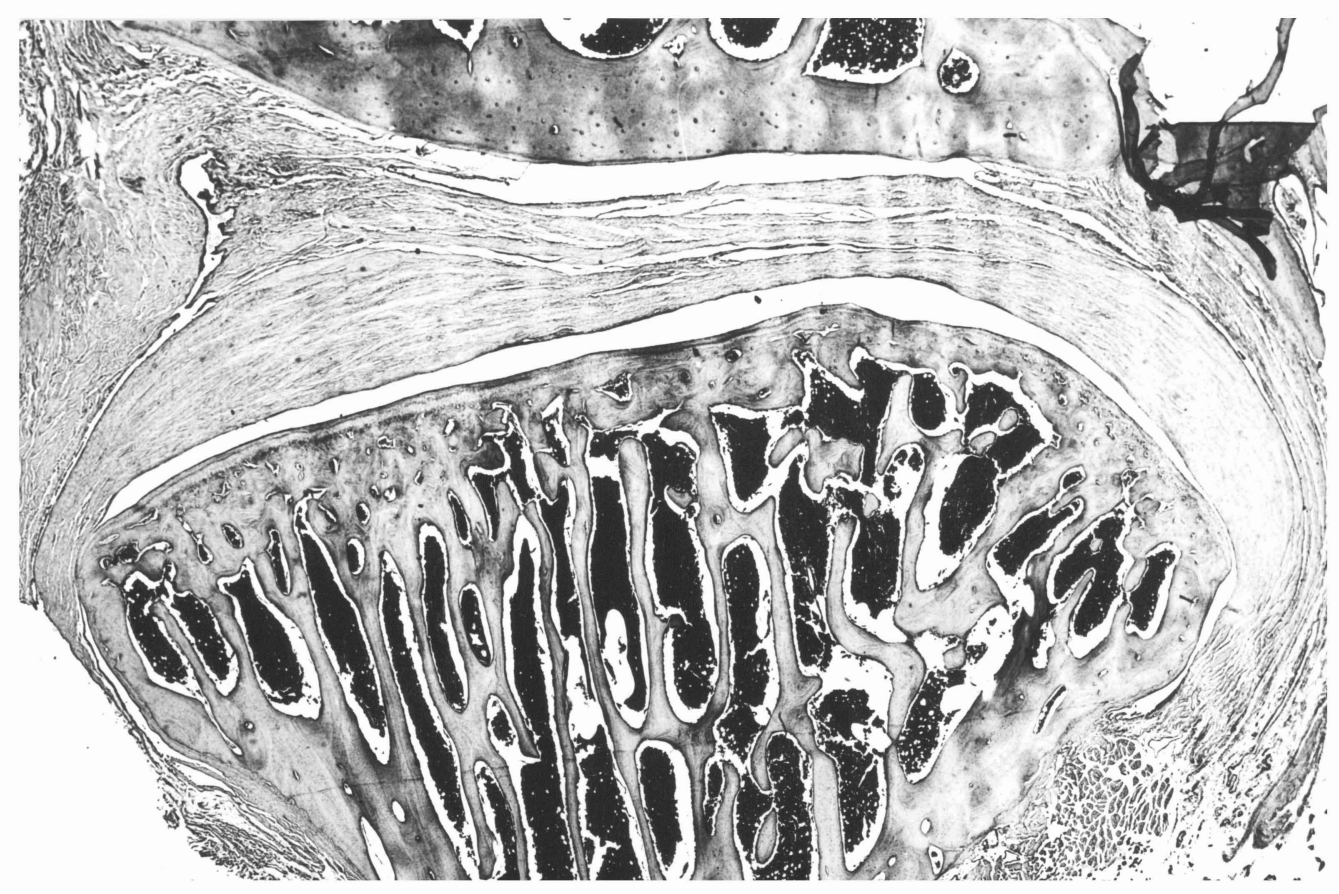

Fig. 18 


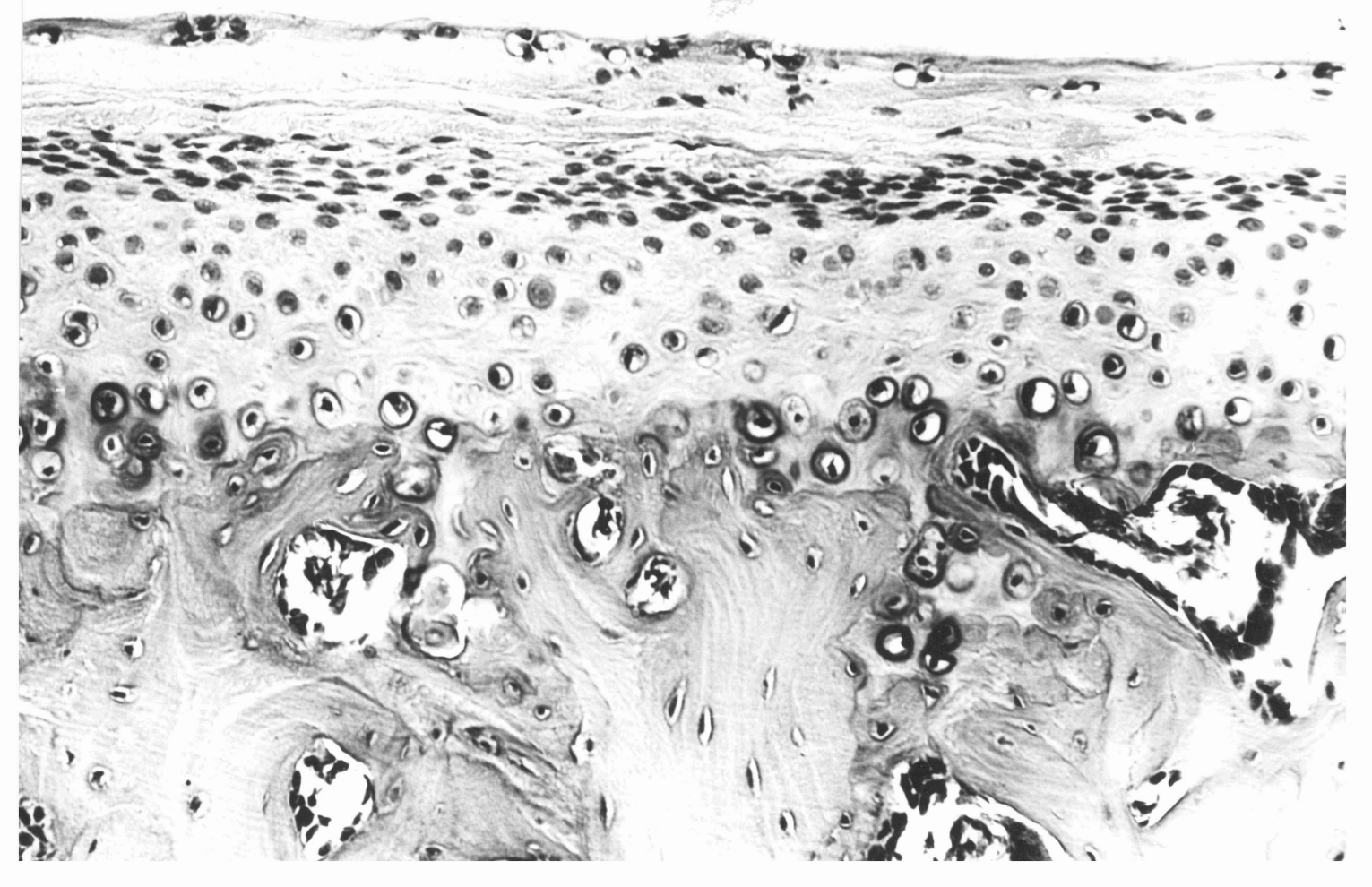

Fig. 19

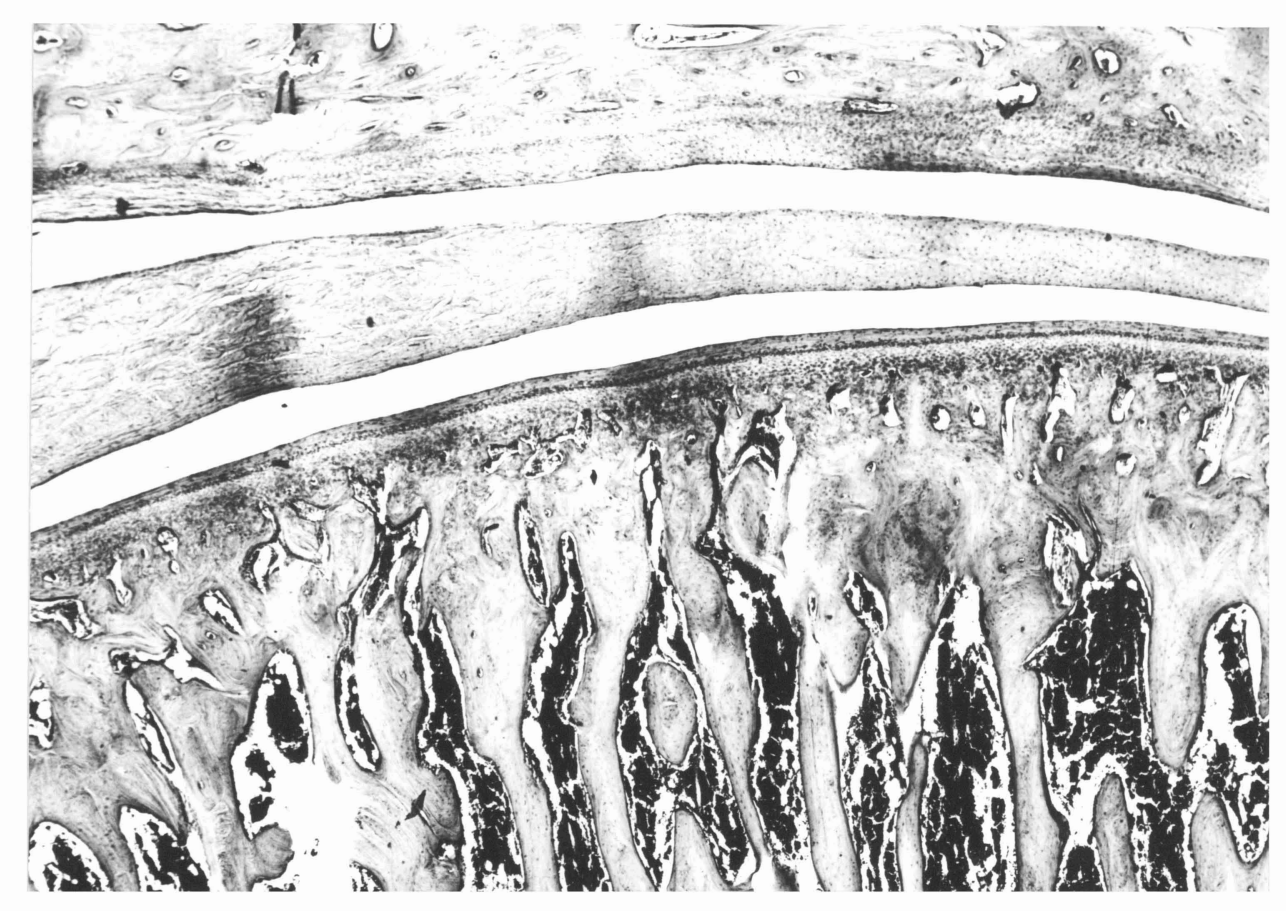




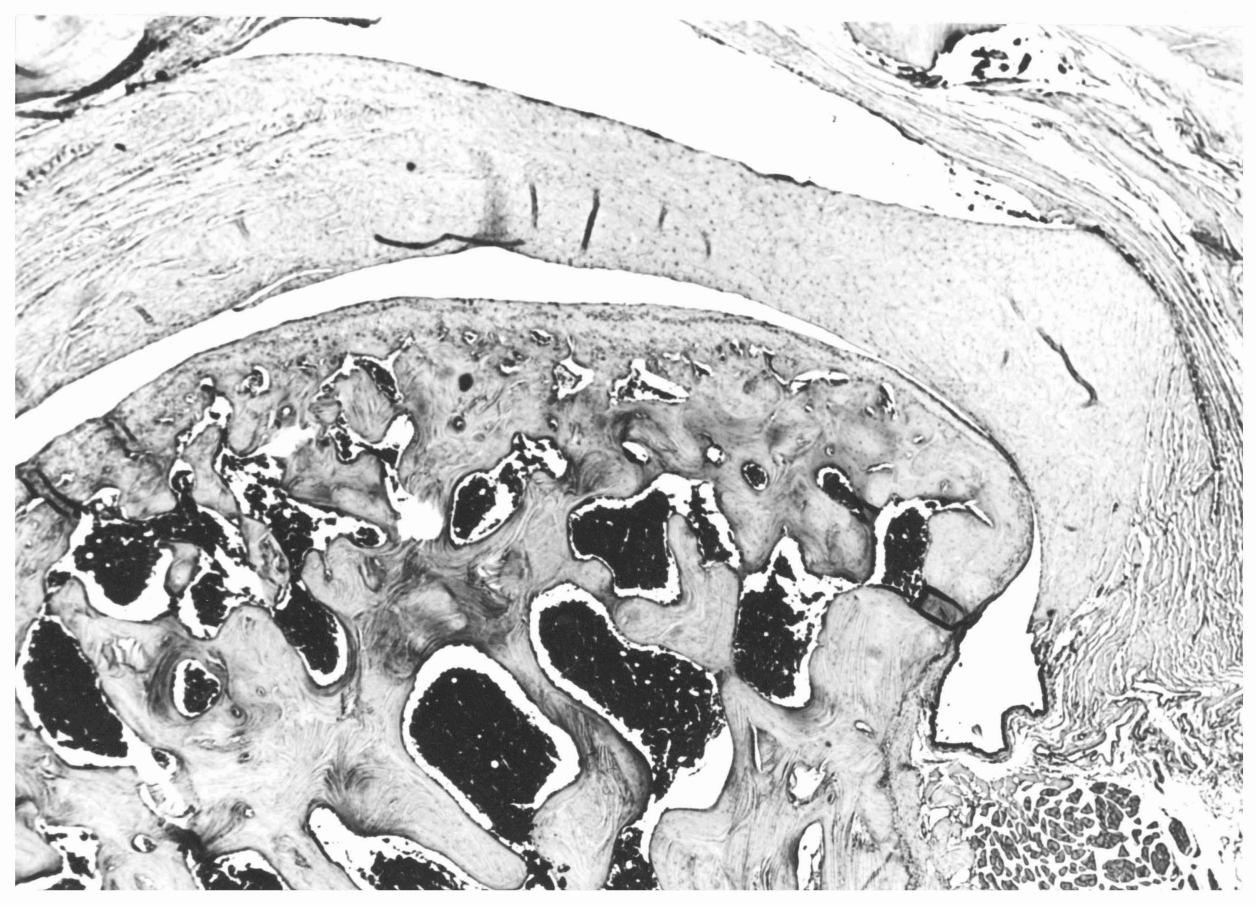

Fig. 21

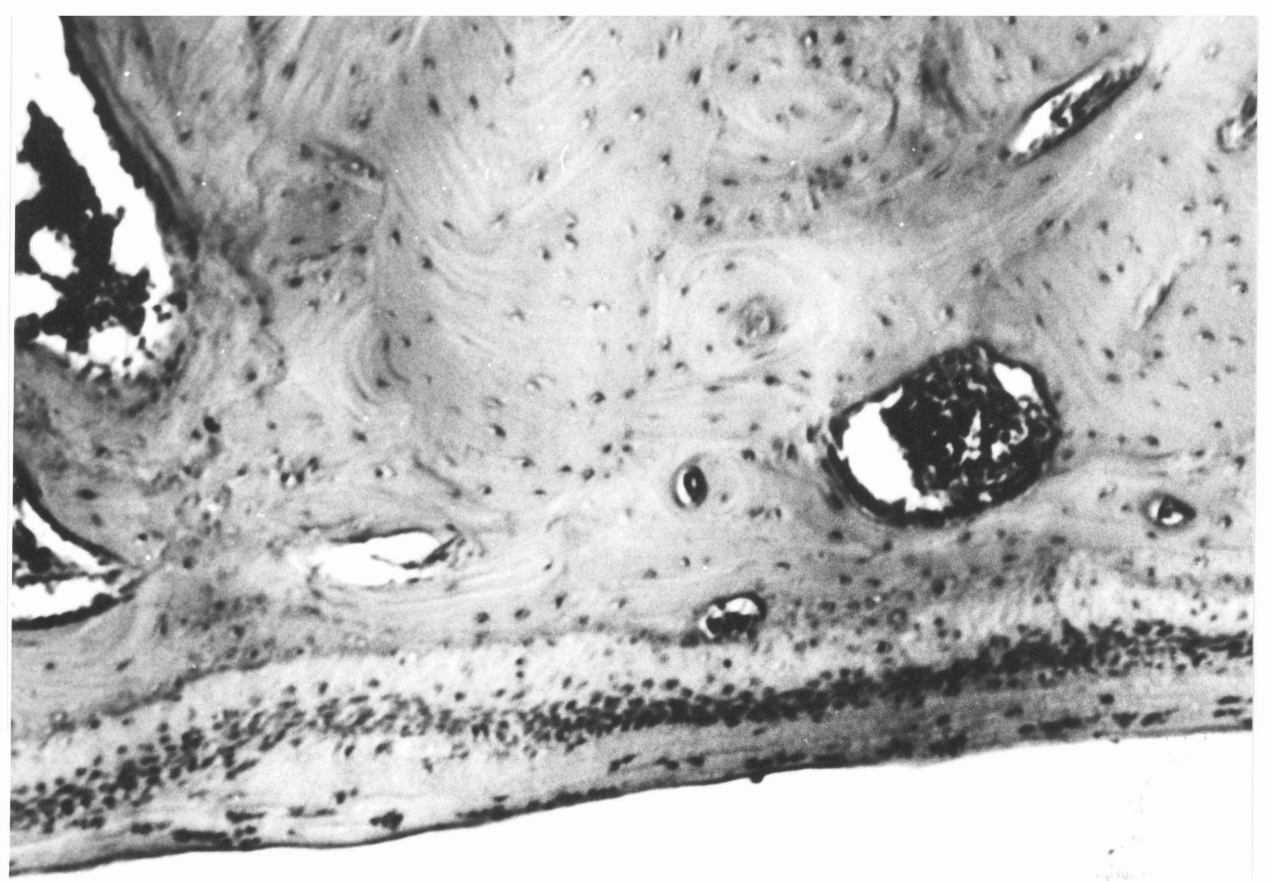

Fig. 22 


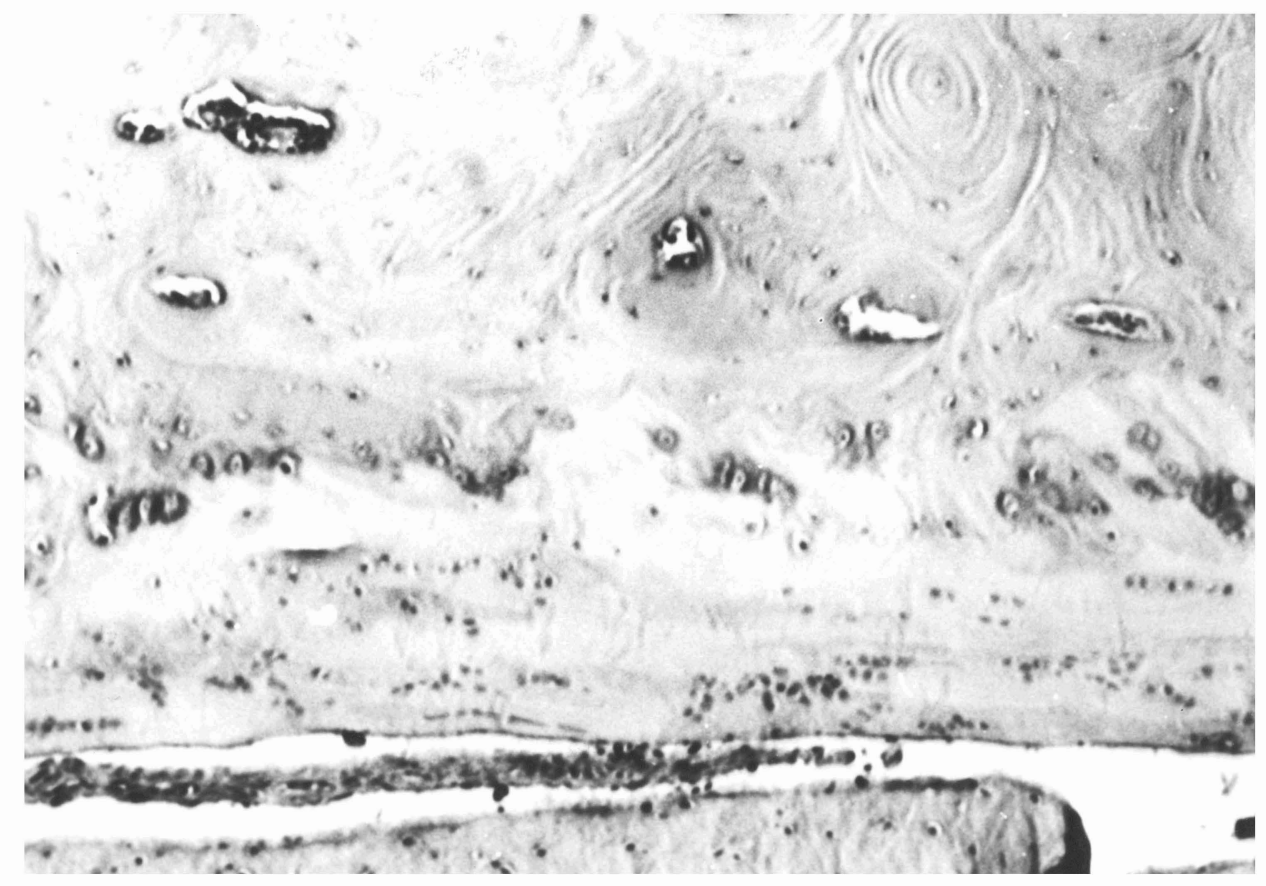

Fig. 23 


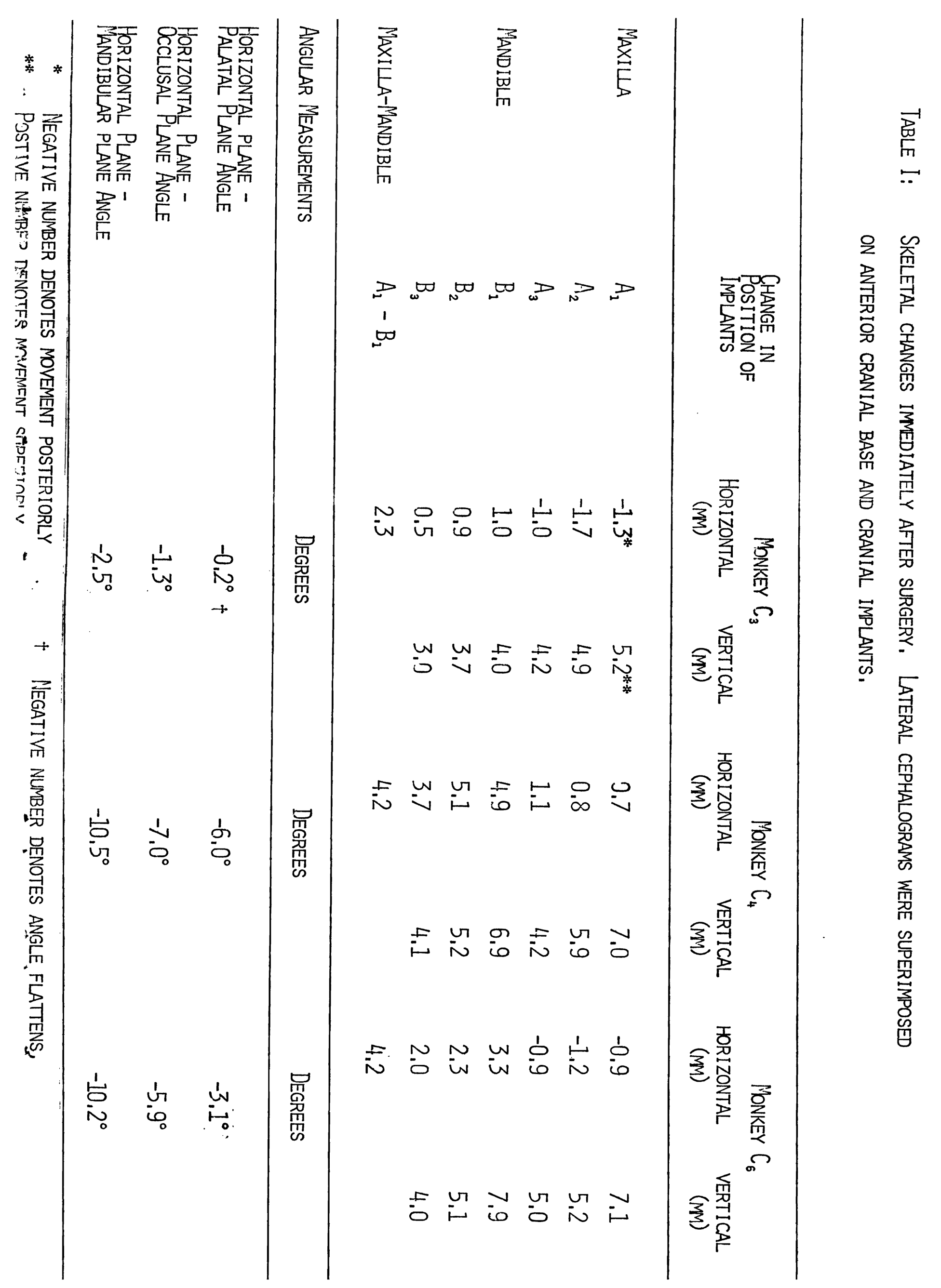




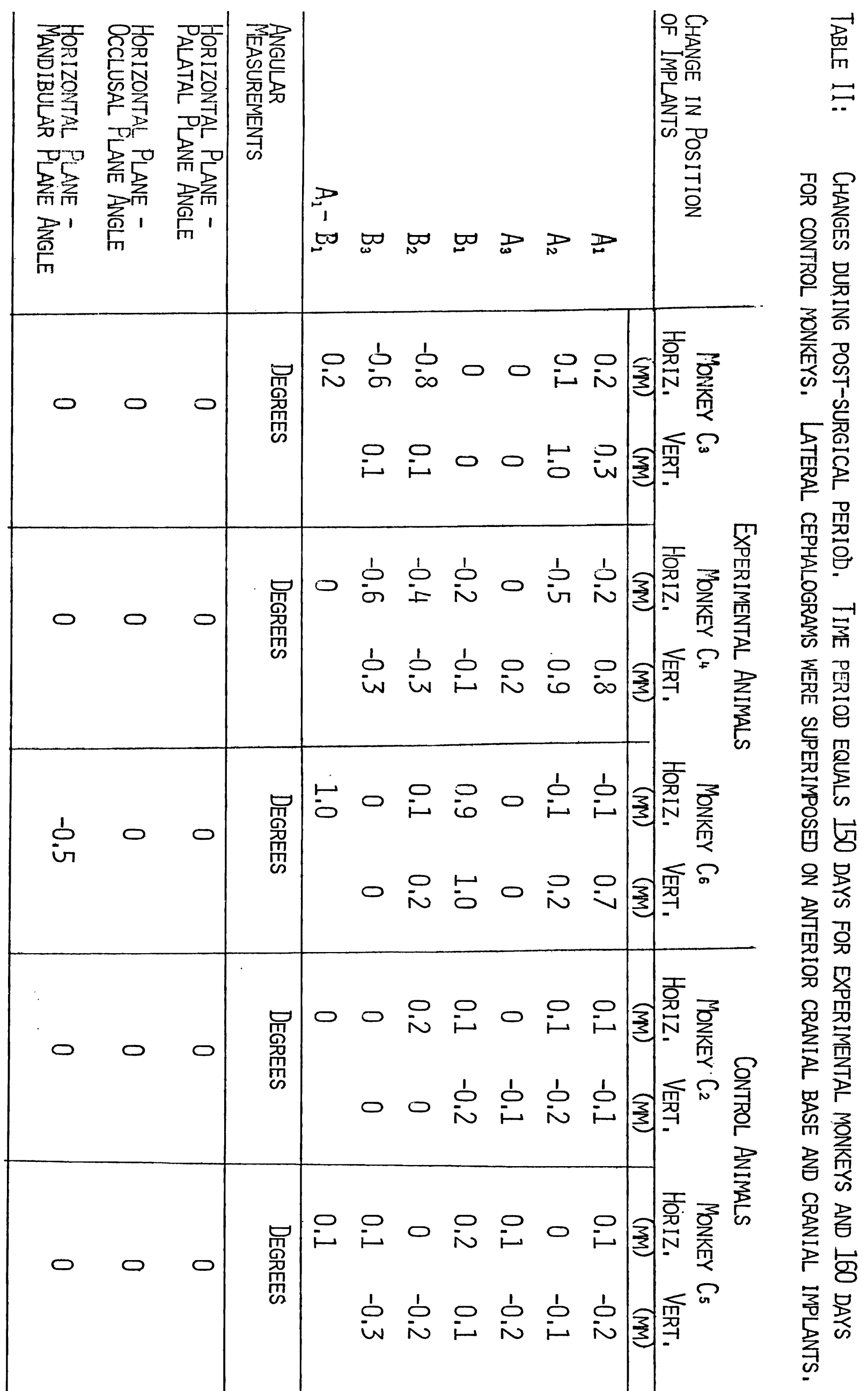




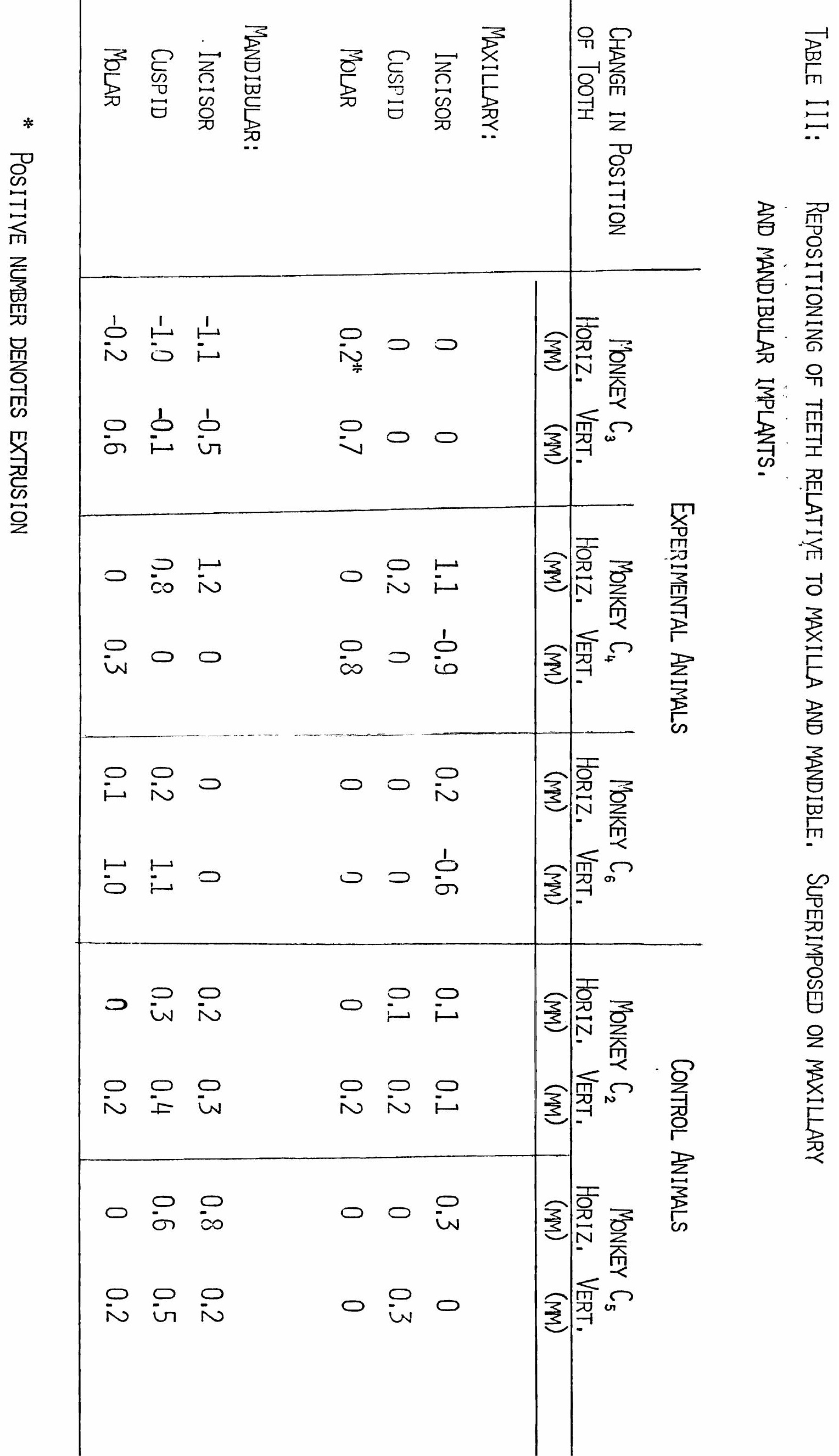

